\title{
Business and consumer expectations and macroeconomic forecasts
}

\author{
Oscar Claveria: \\ Grup d'Anàlisi Quantitativa Regional (AQR) \\ Espai de Recerca en Economia \\ Facultat de Ciències Econòmiques i Empresarials, Universitat de Barcelona \\ E-mail: oclaveria@ub.edu \\ Tel: +34 934021825 \\ Fax: +34 934021821

\section{Ernest Pons:} \\ Grup d'Anàlisi Quantitativa Regional (AQR) \\ Espai de Recerca en Economia \\ Facultat de Ciències Econòmiques i Empresarials, Universitat de Barcelona \\ E-mail: epons@ub.edu \\ Tel: +34 934021412 \\ Fax: +34 934021821

\section{Raúl Ramos:} \\ Grup d'Anàlisi Quantitativa Regional (AQR) \\ Espai de Recerca en Economia \\ Facultat de Ciències Econòmiques i Empresarials, Universitat de Barcelona \\ E-mail: rramos@ub.edu \\ Tel: +34 934021984 \\ Fax: +34 934021821

\section{Address for correspondence} \\ Grup d'Anàlisi Quantitativa Regional (AQR) \\ Espai de Recerca en Economia \\ Facultat de Ciències Econòmiques i Empresarials, Universitat de Barcelona \\ Avda. Diagonal 690 - 08034 Barcelona, Espanya \\ Tel: +34934021012 \\ Fax: +34 934021821
}

Revised version: March 2006 
Biographical sketches:

\section{Oscar Claveria:}

Research fellow at the Grup d'Anàlisi Quantitativa Regional and assistant professor in the Department of Econometrics at the University of Barcelona. His teaching areas are mainly on Statistics and Econometrics. His research interests are focused on forecast quantitative and qualitative variables, econometrics and time series methods and conjuncture analysis. He has collaborated in different research projects related to the quantification of expectations and published part of his research in Cuadernos Aragoneses de Economía and Economic Issues.

\section{Ernest Pons:}

Research fellow at the Grup d'Anàlisi Quantitativa Regional and assistant professor in the Department of Econometrics at the University of Barcelona. His teaching areas are mainly on Statistics and Econometrics. His research interests are focused on the treatment of seasonality and on forecasting quantitative and qualitative variables, econometrics and time series methods and conjuncture analysis using indicators. He has collaborated in different research projects and has published his research in Economics Letters, Información Comercial Española, Revista de Economía Aplicada, Revista Asturiana de Economía and Economic Issues..

\section{Raúl Ramos:}

Research fellow at the Grup d'Anàlisi Quantitativa Regional and assistant professor in the Department of Econometrics at the University of Barcelona. His teaching areas are mainly on Statistics and Econometrics. His research interests are focused on forecasting, monetary policy and regional labour markets. He has participated in different research projects, published in Applied Economics, Economics Letters, Eastern European Economics, Papers in Regional Science, and Regional Studies, and acted as a referee of Journal of Comparative Economics, Papers in Regional Science, and Regional Studies, among others. 
Business and consumer expectations and macroeconomic forecasts 
Abstract:

Business and consumer surveys have become an essential tool for gathering information about different economic variables. While the fast availability of the results and the wide range of variables covered made them very useful for monitoring the current status of the economy, there is no consensus on their utility for forecasting macroeconomic developments.

The objective of the paper is to analyse the possibility of improving forecasts for selected macroeconomic variables for the euro area using the information provided by these surveys. After analyzing the potential presence of seasonality and the issue of quantification, we have tested if these indicators provide useful information to improve forecasts of the macroeconomic variables. With this aim, different sets of models have been considered (AR, ARIMA, SETAR, Markov switching regime models and VAR) to obtain forecasts for the selected macroeconomic variables. Then, information from surveys has been considered to forecast these variables in the context of the following models: autoregressive, VAR models, Markov Switching Regime models and leading indicators models. In both cases, the Root Mean Square Error (RMSE) has been computed for different forecast horizons.

The comparison of the forecasting performance of the two sets of models permit to conclude that in most cases, models that include information from the survey obtain lower RMSE than the best model without survey information. However, this reduction is only significant in a limited number of cases. In this sense, the obtained results extend the results of previous research that have considered information from business and consumer surveys to explain the behaviour of macroeconomic variables, but are not conclusive about its role.

Keywords: Macroeconomic forecasts, forecast competition, business and consumer surveys.

JEL classification: $\quad \mathrm{C} 53, \mathrm{C} 42$ 


\section{Introduction and objectives}

Business and consumer surveys have become an essential tool for gathering information about different economic variables. While the fast availability of the results and the wide range of variables covered make them very useful for monitoring the current status of the economy, there is no consensus on their utility for forecasting macroeconomic developments.

The objective of the paper is to analyse the possibility of improving the forecasts for some selected macroeconomic variables for the euro area using the information provided by business and consumer surveys. As pointed out by Pesaran (1987), this type of data are less likely to be susceptible to sampling and measurement errors than surveys that require respondents to give point forecasts for the variables in question. One can think that the information provided by qualitative indicators could be useful to improve forecasts for quantitative variables due to two reasons. First, statistical information from business and consumer surveys is available much more in advance to quantitative statistics; and, second, these indicators are usually related with agents' expectations, so they are likely to bear a relation to future developments of macroeconomic variables.

In this paper, we have considered all the information available for the business and consumer surveys indicators in the euro area. The dataset analysed includes 38 indicators (33 of which are monthly and 5 quarterly) and 6 composite indicators. Although the starting date of these indicators differs, most of them begin in January 1985 (or in the first quarter of 1985). The latest period to be included in the analysis is December 2005 (or the last quarter of 2005). ${ }^{1}$ More details on the dataset can be found in Table 1 .

\section{TABLE 1}

The strategy to test if these indicators provide useful information to improve forecasts of the macroeconomic variables has been the following:

First, macroeconomic variables that could be related with the information provided by business and consumer surveys have been selected and statistical information for the longest time-span available has been collected from the Eurostat and the ECB databases. ${ }^{2}$ Tables 2 and 3 show more details about this dataset of macroeconomic variables and the correspondence between the business and consumer surveys indicators and these macroeconomic variables. 
TABLES 2 and 3

Second, five different sets of models have been considered (AR, ARIMA, Self-exciting threshold autoregressions -SETAR-, Markov switching regime models and vector autoregressions -VAR-) to obtain forecasts for the different quantitative variables and the Root Mean Square Error (RMSE) and the Mean Absolute Percentual Error (MAPE) have been computed for different forecast horizons. The comparison of these values with the ones obtained with models where information from business and consumer surveys has been considered would permit to assess whether these indicators permit to improve the forecasts or not.

Fourth, information from surveys is considered to forecast the quantitative variables using three different types of models:

(i) Lagged selected indicators are introduced as explanatory variables in autoregressive and VAR models. For Markov Switching Regime models, the probability of changing regime depends on the information of the qualitative indicators rather than on the own evolution of the series.

(ii) Leading indicators models are constructed for each of the quantitative variables using information from business and consumer surveys indicators.

(iii) One problem with survey data is that, in contrast to other statistical series, their results are weighted percentages of respondents expecting an economic variable to increase, decrease or remain constant. Therefore, the information refers to the direction of change but not to its magnitude. And this is the reason why we think that the considered list of qualitative indicators should be previously quantified in order to obtain more reliable forecasts of businessmen' opinions. The conversion of qualitative data into a quantitative measure of the expected rate of change provides more detailed information about agents' opinions and intentions. For this reason, a third strategy to improve quantitative forecasts from qualitative indicators would consist in quantifying the information provided by business and consumer surveys. There have been different proposals in the literature on how to obtain these quantified series of expectations. In this sense, one common feature of all them is that they permit to obtain directly one-period forecasts. 
Another possibility consists in using the quantified series of expectations as explanatory variables of the related quantitative variable.

One additional aspect that has also been considered is whether raw data or seasonal adjusted data from business and consumer surveys should be used in order to improve forecasts of the selected macroeconomic variables.

The structure of the paper is as follows. In the next section our methodological approach is described, including both benchmark models and models where business and consumer surveys information is included. Next, results of the forecasting competition are discussed in Section 3. Last, conclusions are given in Section 4.

\section{Methodology}

\subsection{Benchmark models}

The five proposed models (AR, ARIMA, SETAR, Markov switching regime models and VAR models) have been applied to obtain forecasts for the quantitative variables (expressed as year-onyear growth rates.

\subsubsection{Autoregressions}

The widely known autoregressive model (also known as distributed-lags model) explains the behaviour of the endogenous variable as a linear combination of its own past values:

$$
x_{t}=\phi_{1} x_{t-1}+\phi_{2} x_{t-2}+\ldots+\phi_{p} x_{t-p}+\varepsilon_{t}
$$

The key question is how to determine the number of lags that should be included in the model. For monthly data, we have considered different models with a minimum number of 1 lag up to a maximum of 24 (including all the intermediate lags), selecting that model with the lowest value of the Akaike Information Criteria (AIC). For quarterly data, we have considered a maximum number of lags equals to 8 . 


\subsubsection{ARIMA models}

Since the work by Box and Jenkins (1970), ARIMA models have been widely used and their forecast performance has also been confirmed.

The general expression of an ARIMA model is the following:

$$
x_{t}^{\lambda}=\frac{\Theta_{s}\left(L^{s}\right) \theta(L)}{\Phi_{s}\left(L^{s}\right) \phi(L) \Delta_{s}^{D} \Delta^{d}} \varepsilon_{t}
$$

where

$$
\Theta_{s}\left(L^{s}\right)=\left(1-\Theta_{s} L^{s}-\Theta_{2 s} L^{2 s}-\ldots-\Theta_{Q s} L^{Q s}\right)
$$

is a seasonal moving average polynomial,

$$
\Phi_{s}\left(L^{s}\right)=\left(1-\Phi_{s} L^{s}-\Phi_{2 s} L^{2 s}-\ldots-\Phi_{P s} L^{P s}\right)
$$

is a seasonal autoregressive polynomial,

$$
\theta(L)=\left(1-\theta_{1} L^{1}-\theta_{2} L^{2}-\ldots-\theta_{q} L^{q}\right)
$$

is a regular moving average polynomial,

$$
\phi(L)=\left(1-\phi_{1} L^{1}-\phi_{2} L^{2}-\ldots-\phi_{p} L^{p}\right)
$$

is a regular autoregressive polynomial, $\lambda$ is the value of the Box-Cox (1964) transformation, $\Delta_{s}^{D}$ is the seasonal difference operator, $\Delta^{d}$ is the regular difference operator, $S$ is the periodicity of the considered time series, and $\varepsilon_{t}$ is the innovation which is assumed to behave as a white noise.

In order to use this kind of models with forecasting purposes it is necessary to identify the best suited model (i.e., to give values to the order of the different polynomials, to the difference operator, etc.). For monthly data, we have considered models with up to 12 AR and MA terms (4 in 
the case of quarterly data) selecting the model with the lowest value of the AIC. The statistical goodness of the selected model has also been checked.

\subsubsection{TAR models}

In the case of the ARIMA model the relationship between the current value of a variable and its lags is supposed to be linear and constant over time. However, when looking at real data it can be seen that expansions are more prolonged over time than recessions (Hansen, 1997). In fact, in the behaviour of most economic variables there seems to be a cyclical asymmetry that lineal models are not able to capture (Clements and Smith, 1999).

A Self-Excited Threshold Autoregressive model (SETAR) for the time series $x_{t}$ can be summarised as follows:

$$
\begin{aligned}
& B(L) \cdot x_{t}+u_{t} \text { if } x_{t-k} \leq x(7) \\
& \zeta(L) \cdot s_{t}+v_{t} \text { if } x_{t-k}>x(8)
\end{aligned}
$$

where $u_{t}$ and $v_{t}$ are white noises, $B(L)$ and $\zeta(L)$ are autoregressive polynomials, the value $k$ is known as delay and the value $x$ is known as threshold.

This two-regime self-exciting threshold autoregressive process is estimated using monthly and quarterly data for each indicator and the Monte Carlo procedure is used to generate multi-step forecasts.

The selected values of the delay are those minimising the sum of squared errors among values between 1 and 12 for monthly data and 1 and 4 for quarterly data. The values of the threshold are given by the variation of the analysed variable.

\subsubsection{Markov switching regime models}

Threshold autoregressive models are perhaps the simplest generalization of linear autoregressions. In fact, these models were built on developments over traditional ARMA time series models. As an alternative to these models, time series regime-switching models assume that the distribution of the 
variable is known conditional on a particular regime or state occurring. When the economy changes from one regime to another, a substantial change occurs in the series.

Hamilton (1989) presented the Markov regime-switching model in which the unobserved regime evolves over time as a 1st-order Markov process. The regime completely governs the dynamic behaviour of the series. This implies that once we condition on a particular regime occurring, and assume a particular parameterization of the model, we can write down the density of the variable of interest. However, as the regime is strictly unobservable, it is necessary to draw statistical inference regarding the likelihood of each regime occurring at any point in time. So, it is necessary to obtain the transition probabilities from one regime to the other.

There have been three different approaches to estimating these models (Potter, 1999). First, Hamilton (1989) developed a nonlinear filter to evaluate the likelihood function of the model and then directly maximized the likelihood function. Second, in a later article, Hamilton (1990) constructed an EM algorithm that is particularly useful for the case where all the parameters switch. Finally, Albert and Chib (1993) developed a Bayesian approach to estimation.

In this work, we employ a Markov-switching threshold autoregressive model (MK-TAR) where we allow for different regime-dependent intercepts, autoregressive parameters, and variances. The estimation of the models is carried out by maximum likelihood using the Hamilton (1989) filter ${ }^{3}$ together with the smoothing filter of Kim (1994).

Once we have estimated the probabilities of expansion and recession, we construct the following model for the time series $x_{t}$ using the estimated probabilities of changing regime:

$$
\begin{aligned}
& B(L) \cdot x_{t}+u_{t} \text { if } P\left[\text { Expansion } / x_{t-k}\right] \leq P \\
& \zeta(L) \cdot x_{t}+v_{t} \text { if } P\left[\text { Expansion } / x_{t-k}\right]>P
\end{aligned}
$$

where, as in SETAR models, $u_{t}$ and $v_{t}$ are white noises, $B(L)$ and $\zeta(L)$ are autoregressive polynomials, the value $k$ is known as delay and the value $P$ is known as threshold. ${ }^{4}$ The selected values of the delay are those minimising the sum of squared errors among values between 1 and 12 for monthly data and 1 and 4 for quarterly data. The values of the threshold are given by the variation of the probability. 


\subsubsection{VAR models}

The VAR models that have been specified try to pick up, as far as possible, the classical Economic Theory assumptions in order to reflect the economic dynamic. In this sense, the VAR models that have been estimated could be defined as "total of the economy", "supply", "industry", "construction" and, by the demand side, "exports", "consumption" and "saving". In particular, the considered quantitative VAR models are shown in table 4.

\section{TABLE 4}

\subsection{Models where business and consumer surveys information is incorporated}

\subsection{1. "Augmented” autoregression, Markov switching regime and VAR models}

One way to use the information of the qualitative indicators to improve the forecasts of the quantitative variables consists in introducing selected indicators as explanatory variables in autoregressions and VAR models. Recently, different works have estimated autoregressive and VAR models for some target variable (consumer spending, GNP), adding current and lagged values of a consumer confidence index to the models in order to test its significance and consider the extent of its effects. The approach applied in this section is quite similar. In this sense, it is worth mentioning that, as shown in table 2, more than one quantitative variable could be related to the evolution of the considered indicators. So, different possibilities have been considered for each autoregressive model. For the case of "augmented" VAR models, the strategy has been slightly different: only selected indicators have been included. This information is shown in table 5 .

\section{TABLE 5}

\subsubsection{Leading indicators models}

In spite of their well-known limitations pointed by the literature, leading indicators can also provide reliable forecasts of the analysed quantitative variables considering the whole set of information of business and consumer surveys. 
According to Clements and Hendry (1998), p. 207 "an indicator is any variable believed informative about another variable of interest". In this context, a leading indicator is any variable whose outcome is known in advance of a related variable which is desired to forecast. Usually, there are several leading indicators for every variable to be forecasted and, for this reason, composite leading indicators are constructed. A composite leading index is a combination (e.g. a weighted average) of this set of simple leading indicators. Composite leading indicators are useful to provide estimates of the current state and short-term forecasts of the analysed economy. The main advantage of composite leading indicators in relation to other methods is that it is not necessary to obtain forecasts for exogenous variables as their lagged values are known in advance. Of course, leading indicators will only provide reasonably accurate short term forecasts. However, we extend the analysis up to two years as an additional benchmark for the results using other procedures.

The procedure for the selection of the simple leading indicators for each endogenous variable is based on the bilateral correlations between different lags of each of the variables in the business and consumer surveys indicators and the endogenous variable. The simple leading indicators have been chosen among those with highest values of the correlation coefficient. The length of the lead has been determined by cross-correlation analysis. In this sense, as an automatic identification procedure, different values of the bilateral correlation coefficient have been explored as a limit for a variable to be considered as a leading indicator. These values range from zero (all explanatory variables would be considered as leading indicators) to 0.8 (only variables with a strong correlation with the endogenous would be considered). Eventually we fixed this limit at 0.5 .

As there could be several simple leading indicators for every endogenous variable and the available sample is quite short, it is necessary to reduce the dimensionality of the exogenous variables matrix before using this information set to obtain the desired forecasts. It is also necessary to eliminate from this set of simple leading indicators, the part of their behaviour attributable to noise which would not be useful to forecast the endogenous variables (the noise would be higher with lower values of the correlation coefficient). With this aim, we extracted the principal components of the explanatory variables. The idea is that the first principal components capture the commonalities in the set of simple leading indicators (the relevant information to forecast the endogenous variables). After experimenting with different values, we retain as many components as necessary to explain $70 \%$ of the total variance of the simple leading indicators. 
Once the simple leading indicators have been selected and have been summarised in a few components (in most cases, the number of considered components ranges from one to three), these components are used as explanatory variables in the forecasting equations.

The description of the leading indicators models applied in this case and their selected variables are available from the authors on request.

\subsection{Other aspects related to the nature of business and consumer surveys indicators}

\subsubsection{Seasonal patterns}

One feature of business and consumer survey data is the presence of seasonal patterns. The treatment of seasonal patterns is relevant in our context in order to determine whether is better to forecast macroeconomic variables using raw data or seasonal adjusted data. In order to verify the importance of seasonality, we computed the Kruskal-Wallis test for all the indicators in our database. Table 6 summarises the obtained results (more details are given in Annex A). As it can be seen in this table, in almost an $80 \%$ of the cases, the null hypothesis of non-seasonality was not rejected, that is, most series did not present a seasonal component. Taking into account these results, and in order to keep homogeneity, in our forecasting competition we decided to use raw data for all the indicators obtained from the surveys.

\section{TABLE 6}

\subsubsection{Quantification of expectations}

An additional problem with survey data is that, in contrast to other statistical series, their results are weighted percentages of respondents expecting an economic variable to increase, decrease or remain constant. Therefore, the information refers to the direction of change but not to its magnitude. In the literature, different methods have been proposed in order to convert qualitative data into a quantitative measure of agents' opinions and intentions. The problem with these methods is that only one-period forecasts can be directly computed (for further details, see Claveria et al., 2006), and for this reason, in this paper, the quantification of expectations will only be used to transform survey indicators before including them as regressors in autoregressions and VAR models. With this aim, six different possibilities are considered: the balance, the principal 
components based procedure, the Anderson procedure, the Carlson-Parkin and Augmented CarlsonParkin methods and State-Space models.

Assuming that the percentage change expected remains constant in time for the categories expecting an increase and a decrease of the variable, Anderson (1951) defined the balance statistic as a measure of the average changes expected in the variable. Ever since, the balance statistic has been widely used as a short-term forecast as well as for the construction of several economic indicators.

There have been a variety of quantification methods proposed in the literature. These methods are based on the assumption that respondents base their answer on a subjective probability distribution defined over future changes in the variable and conditional to the information available up to that moment, which has the same form for all agents. Differences between methods have usually been related to theoretical considerations regarding rationality tests rather than based on their forecasting ability.

The accuracy of the balance statistic as a means for extracting the maximum degree of information from survey data on the direction of change has been widely studied since the introduction of this new source of information in Europe by the IFO-Institut für Wirtschaftsforschung at the beginning of the fifties, for example by Anderson (1951, 1952), Theil (1952, 1955), Anderson, Bauer and Fels (1954), De Menil and Bhalla (1975) and Defris and Williams (1979). This line of research has led some authors to look for alternative procedures and statistics oriented towards the conversion of qualitative data into quantitative series of expectations.

While most of the emphasis was given to the justification of the balance statistic within a theoretical framework and the evaluation of its performance as predictor of inflation and economic activity, as well as to the analysis of the rationality and the formation of expectations (i.e. Papadia, 1983), some other studies have been more empirically oriented. The fact that business and consumer surveys seem to be a valuable tool for anticipating economic activity has given rise to a line of research more focused on the construction of indexes and indicators of activity with survey data.

In spite of the valuable information contained in the balance statistic, our experience with this type of data has led us to find some limitations of the balance statistic as a forecasting measure. Some of these shortcomings concerning the degree of response, the relative importance of each category for every question, etc. depend to a large extent on the specific features of the survey under 
consideration. Some other problems, such as the volatility and the escalation of the series, are related to the nature of the data on the direction of change.

For this reason, we have considered other possibilities of "quantifying" the information from business and consumer surveys. A first possibility consists in summarising all the possible answering categories contained in the business and consumer surveys in an indicator that also takes account of the percentage of "stable" answers. This indicator can be constructed using a principal component analysis (PCA) of all the answers for each question, which shows the linear combination of the three/five/six percentages that captures the most variability between the successive surveys.

But, the strong correlation of the balance statistic with the percentage changes of its corresponding quantitative index of reference found by Anderson (1952) opened the door for the quantification of ordinal responses using more complex methods. Theil (1952) suggested a theoretical framework, later referred as the subjective probability approach, to convert qualitative responses of the direction of change into quantitative expectations, $\bar{x}_{t+1}^{e}$. The basic idea behind the method is that there is some indifference interval around zero within which respondents report "no change", whereas outside they report a change in the variable.

Let $x_{t+1}$ be the percentage change of the variable from period $t$ to period $t+1$ and $x_{t+1}^{e}$ its expectation conditional on the respondent's information set. Hence, an expected increase is reported if $\bar{x}_{t+1}^{e}>\delta_{a}$ with a relative frequency $A_{t}^{t+1}$ and an expected decrease $\bar{x}_{t+1}^{e}<\delta_{b}$ with a relative frequency $B_{t}^{t+1}$. Assuming the standard normal distribution one can derive:

$$
\bar{x}_{t+1}^{e}=\hat{\delta} \hat{g}_{t}^{t+1}
$$

where $g_{t}^{t+1}=\frac{b_{t}^{t+1}+a_{t}^{t+1}}{b_{t}^{t+1}-a_{t}^{t+1}}$ and $\left\{\begin{array}{l}b_{t}^{t+1}=\Phi^{-1}\left(B_{t}^{t+1}\right)=\frac{-\delta-\bar{x}_{t+1}^{e}}{\sigma_{t+1}^{e}} \\ a_{t}^{t+1}=\Phi^{-1}\left(1-A_{t}^{t+1}\right)=\frac{\delta-\bar{x}_{t+1}^{e}}{\sigma_{t+1}^{e}}\end{array}\right.$.

$\Phi^{-1}$ stands for the inverse of the cumulative standard normal distribution. As pointed out by Zimmermann (1999), the logistic and the scaled- $t$ have also been used in the literature, usually leading to very similar results. Since the limit of the interval of indifference $\delta$ is unknown, Carlson and Parkin (1975) used the following method of escalation: 


$$
\delta=\frac{\sum_{t=1}^{n} x_{t+1}}{\sum_{t=1}^{n} g_{t}^{t+1}}
$$

This method was first applied by Carlson and Parkin (1975) and widely employed in the literature ever since. Recent contributions have relaxed the assumption of a symmetric indifference interval and the unbiasedness condition introduced by Carlson-Parkin escalating procedure:

$$
x_{t+1}^{e}=\hat{\delta}_{b} e_{t}^{t+1}+\hat{\delta}_{a} f_{t}^{t+1}
$$

where $e_{t}^{t+1}=\frac{b_{t}^{t+1}}{b_{t}^{t+1}-a_{t}^{t+1}}$ and $f_{t}^{t+1}=\frac{a_{t}^{t+1}}{b_{t}^{t+1}-a_{t}^{t+1}}$.

As parameters $\delta_{b}$ and $\delta_{a}$ are unknown they have to be estimated usually by the following OLS regression $x_{t}=\delta_{b} t_{t}^{t-1}+\delta_{a} f_{t}^{t-1}+u_{t}$. This alternative procedure implies that the aggregate distribution and the indifference intervals for both expectations and realizations are the same. As it happened with Carlson-Parkin method, this may cause problems when using the derived data for testing the rationality of expectations.

Recent econometric techniques have been incorporated in the methodology in order to overcome some of its shortcomings, basically the restrictive assumptions on which it is based. As a result, new methods have been suggested and applied with the aim of obtaining accurate series of expectations. Recent papers have focused in the possibility of using State-Space models to estimate series of expectations and to forecast reference quantitative variables. For example, Seitz (1988) applied the time-varying parameter model of Cooley and Prescott (1976) and used the Kalman filter to derive a dynamic and asymmetric indifference interval.

Our proposal consists in using a State-Space model where the Kalman filter is used to estimate time varying and asymmetric indifference intervals that can be used to obtain series of expectations but also to forecast reference quantitative series. 
By relaxing the assumption that thresholds $\delta_{a, t+1}$ and $\delta_{b, t+1}$ are symmetric and are fixed across time, the asymmetric Carlson-Parkin conversion equation turns into:

$$
x_{t+1}^{e}=\hat{\delta}_{b} e_{t}^{t+1}+\hat{\delta}_{a} f_{t}^{t+1}
$$

where $e_{t}^{t+1}=\frac{b_{t}^{t+1}}{b_{t}^{t+1}-a_{t}^{t+1}}$ and $f_{t}^{t+1}=\frac{a_{t}^{t+1}}{b_{t}^{t+1}-a_{t}^{t+1}}$.

Instead of using the Cooley and Prescott time-varying parameter model and regressing the outturn on retrospective survey responses in order to obtain estimates of $x_{t+1}^{e}$ as done by Seitz (1988), we purpose a more general state-space representation for the threshold parameters that would include Seitz's method as a particular case:

$$
\bar{x}_{t}=\delta_{a, t} e_{t-1}^{t}-\delta_{b, t} f_{t}^{t+1}+u_{t}
$$

where $u_{t} \sim N\left(0, \sigma_{u}^{2}\right)$, and

$$
\left\{\begin{array}{l}
\delta_{a, t}=\alpha \delta_{a, t-1}+v_{t} \\
\delta_{b, t}=\beta \delta_{b, t-1}+w_{t}
\end{array}\right.
$$

where $\alpha$ and $\beta$ are the autoregressive parameters and $v_{t}$ and $w_{t}$ are two independent and normally distributed disturbances with mean zero and variance $\sigma_{v}^{2}$ and $\sigma_{w}^{2}$, respectively. The relationship between $x_{t}$ and the response thresholds is linear and it is expressed in the measurement equation. The unknown state is supposed to vary in time according to the linear transition equation. In order to estimate the variances and the autoregressive parameters and derive estimates of $x_{t+1}^{e}$ the Kalman filter is used.

This generalization of the probability approach introduces a more flexible representation, allowing for asymmetric and dynamic response thresholds generated by a first-order Markov process. Additionally, estimates of $\bar{x}_{t+1}^{e}$ can be derived by means of just survey responses about expectations, without the need of perceptions about past changes of the variable. 
We also consider a particular case of this general model where threshold parameters follow a random walk instead of an autoregressive process. Therefore, $\alpha$ and $\beta$ are supposed to be zero and the state-space representation of the model is:

$$
\bar{x}_{t}=\delta_{a, t} e_{t-1}^{t}-\delta_{b, t} f_{t}^{t+1}+u_{t}
$$

where $u_{t} \sim N\left(0, \sigma_{u}^{2}\right)$ and

$$
\left\{\begin{array}{l}
\delta_{a, t}=\delta_{a, t-1}+v_{t} \\
\delta_{b, t}=\delta_{b, t-1}+w_{t}
\end{array}\right.
$$

When initialising the Kalman filter two options have been considered. First, we have supposed that the initial conditions of the filter are obtained by regressing $\bar{x}_{t}$ on $e_{t}^{t+1}$ and $f_{t}^{t+1}$ in the first fourth of the sample. We have also supposed that both initial conditions are equal to zero. As a result, we end up with four different state-space representations:

SS1: autoregressive process with initial conditions estimated by OLS regression.

SS2: random walk process with initial conditions estimated by OLS regression.

SS3: random walk process with null initial conditions.

SS4: autoregressive process with null initial conditions.

Further details on the estimation procedure can be found in Harvey (1982) and (1987).

The output of these quantification procedures can be considered as one period ahead forecasts of the quantitative variable used in the analysis or as exogenous proxies (quantified indicators) introduced in $\mathrm{AR}$ and VAR models to forecast quantitative variables. This second alternative is the one considered in this paper.

\section{Results of the forecasting competition}

In order to evaluate the relative forecasting accuracy of the models, for each variable to be forecasted all models were estimated until 2001.12 (or 2001.III or IV for quarterly indicators) and forecasts for 1,2,3,6 and 12 months (or 1,2,4 quarters) ahead were computed. The specifications of 
the models are based on information up to that date and, then, models are re-estimated in each month or quarter and forecasts are computed. Given the availability of actual values until 2005.12 or 2005.III or IV, forecast errors for each indicator and method can be computed in a recursive way (i.e., for the 1 month forecast horizon, 48 forecast errors can be computed for each indicator or 16 for the 1 quarter forecast horizon). In order to summarise this information, the Root Mean Squared Error (RMSE) has been computed. These values provide useful information in order to analyse the forecast accuracy of each method, so methods can be ranked according to their values. It is worth mentioning that in all cases we have assumed that the information of business and consumer surveys is known in advance, which is not a strong assumption for shorter forecasting horizons but it could be for longer ones. A possible strategy that is beyond the scope of this paper is to apply univariate forecasting methods to business and consumer surveys indicators (see Clar et al., 2006).

The results of our forecasting competition are shown in tables B.1 to B.19 of appendix B. These tables present the values of the Root of the Mean Squared Error (RMSE) obtained from recursive forecasts for 1,2,3,6 and 12 months during the period 2002.1-2005.12 or for 1,2 and 4 quarters during the period 2002.I-2005.IV for both, the benchmark models and the models including information from surveys.

The obtained results permit to conclude that, as expected, forecasts errors increase for longer horizons in most cases. Regarding the forecast accuracy of the different methods, in most cases the autoregressions, leading indicators models and VAR models are not outperformed by the rest of the methods, being the ARIMA and the modified Markov model the ones usually displaying the highest RMSE values.

But, do models with information from business and consumer surveys improve the forecasting performance of models that do not? Table 7 summarises the results from the forecasting competition. In particular, it shows for each variable which is the model with the lower value of the RMSE for every forecasting horizon. As we can see, when comparing the performance of the models including survey data to the ones that do not, the conclusion seems to be that in most cases some model that includes information from the survey obtains lower RMSE than the best model without survey information.

TABLE 7 
In particular, for monthly variables (top panel of table 7) only for forecasting horizons of 1, 2 and 3 months, models without survey information show lower values of the RMSE than models with survey information. The exceptions are the number of persons employed in construction (qv2), the industry production index (qv4) and the number of new car registrations (qv6). For 6 and 12 months forecasting horizons, augmented AR models, augmented VAR models and leading indicator models show a better forecasting performance.

For quarterly variables (bottom panel of table 7), the results show a similar pattern: models with survey information show lower values of the RMSE with some exceptions for 1 quarter forecasting horizon. In particular, autoregressions and VAR models without survey information achieve better results for gross domestic product (qv14), gross fixed capital formation: construction work - other constructions (qv15) and final consumption expenditure: household and NPISH (qv18).

However, one key aspect that should be addressed is if the reduction in RMSE when comparing models with and without survey information is statistically significant. ${ }^{5}$ With this aim, we have calculated the measure of predictive accuracy proposed by Diebold-Mariano (1995) between the two best models with and without survey information for the first 12 months or the first 4 quarters of the forecasting horizon. Given these two competing forecasts and the actual series for each quantitative variable, we have calculated the $S(1)$ measure which compares the mean difference between a loss criteria (in this case, the root of the mean squared error) for the two predictions using a long-run estimate of the variance of the difference series. ${ }^{6}$ In order to estimate this long-run variance from its autocovariance function, we have used the Bartlett kernel, as it guarantees that variance estimates are positive definite, while the maximum lag order has been calculated using the Schwert criterion as a function of the sample size. These results are shown in table 8.

\section{TABLE 8}

If we look at the results from table 8, we can see that in 9 out of 19 cases there is no significant difference between both forecasts. However, in ten cases, the difference is significant and in five of them, this difference is in favour of models with survey information ${ }^{7}$. The actual values and the two competing forecasts for these seven series where the difference is significant are shown in figure 1.

FIGURE 1 
As we can see from table 8 and figure 1, the consideration of information from business and consumer surveys improves significantly the forecasting performance of the considered models but in a similar number of cases than models without survey information. These results are in line with the ones shown in table 7 and in the annex B.

However, looking at figure 1, it can also be observed that information from business and consumer surveys is particularly helpful in the presence of turning points in the forecasting horizon. For example, in the case of the savings rate (qv13), the leading indicator models with survey information is able to capture more quickly the downward trend in its evolution. A similar result is obtained for the gross fixed capital formation (qv15) when the construction confidence indicator (v28) is included as an exogenous variable in a VAR model.

Summarising, the comparison of the forecasting performance of the two sets of models permit to conclude that in most cases, models that include information from the survey obtain lower RMSE than the best model without survey information, particularly at longer forecasting horizons. However, this reduction is only significant in a limited number of cases. In this sense, the obtained results extend the results of previous research that have considered information from business and consumer surveys to explain the behaviour of macroeconomic variables, but are not conclusive about its role.

\section{Conclusions}

The objective of the paper was to analyse the possibility of improving the forecasts for some selected macroeconomic variables for the euro area using the information provided by business and consumer surveys. With this aim, we have carried out a forecasting competition between models with and without survey information and considering the presence or not of seasonal patterns in the data and the need of quantification the information from surveys.

The obtained results allow us to conclude that, only in a limited number of cases, the consideration of information from business and consumer surveys has improved significantly the forecasting performance of the different models for the considered macroeconomic variables.

Last, it is important to highlight that we have extended in a more systematic way ${ }^{8}$ the results of previous research ${ }^{9}$ that have considered information from business and consumer surveys to explain 
the behaviour of macroeconomic variables. As previously mentioned, the consideration of business and consumer surveys reduces the value of the RMSE in nearly the $80 \%$ of cases, but the results are not conclusive in a statistical sense (the reduction of forecasts errors is only significant in a limited number of cases). Moreover, the economic interpretation of the results is not always clear: for example, in the case of the number of persons employed in construction (qv2) when employment expectations for the months ahead (v31) is included as an additional explanatory variable, a significant improvement is achieved in forecasting the future evolution of the macroeconomic variable, which is the expected result. However, in other cases, such as the evolution of industrial production (qv4) and production expectations for the months ahead (v7), although RMSE is reduced, the differences are not significant. Why some survey indicators help to improve forecasts and why others do not is an aspect that will be considered in further research.

\section{Acknowledgements}

The results presented here were obtained under the contract "Forecasting models currently applied to indicators computed on the basis of surveys results" (ECFIN/2002/A3-01), directed by Manuel Artís and Jordi Suriñach, and the full report is available at the following internet address http://europa.eu.int/comm/economy finance/indicators/business_consumer_surveys/studies/ub_aqr final_report.pdf. We would like to thank the editors and an anonymous referee for their helpful comments and also the staff from the DG ECFIN of the European Commission and, particularly, Peter Weiss and Pilar Bengoechea for their suggestions and support. Raúl Ramos gratefully acknowledges support received from CICYT SEJ2005-04348/ECON. The usual disclaimer applies.

\section{References}

Albert, J. and Chib, S. (1993). Bayesian inference via Gibbs sampling of autoregressive time series subject to Markov mean and variance shifts. Journal of Business and Economic Statistics, 11, 1-15.

Anderson, O. (1951). Konjunkturtest und Statistik. Allgemeines Statistical Archives, 35, 209-20.

Anderson, O. (1952). The business test of the IFO-Institute for economic research, Munich, and its theoretical model. Revue de l'Institut International de Statistique, 20, 1-17. 
Anderson, O., Bauer, R. K. and Fels, E. (1954). On the accuracy of short-term entrepreneurial expectations. Paper presented at the Montreal Meeting of the American Statistical Association.

Bodo, G., Golinelli, R. and Parigi, G. (2000). Forecasting Industrial Production in the Euro Area. Empirical Economics, 25, 541-561.

Box, G. and Cox, D. (1964). An Analysis of Transformation. Journal of the Royal Statistical Society Series B, 211-264.

Box, G. E. P. and Jenkins, G. M. (1970). Time Series Analysis: Forecasting and Control. HoldenDay, San Francisco.

Carlson, J. A. and Parkin, M. (1975). Inflation expectations. Economica, 42, 123-38.

Clar, M., Duque, J. C., Moreno, R. (2006), Forecasting Business and Consumer Surveys Indicators. A Time Series Models Competition. Applied Economics, forthcoming.

Claveria, O., Pons, E., Surinach, J. (2006), Quantification of Expectations. Are They Useful for Forecasting Inflation?. Economic Issues, forthcoming.

Clements, M. and Hendry, D. (1998). Forecasting economic time series. Cambridge University Press, Cambridge.

Clements, M. and Smith, J. (1999). A Monte Carlo Study of the Forecasting Performance of Empirical SETAR models. Journal of Applied Econometrics, 14, 123-141.

Cooley, T. F. and Prescott, E. C. (1976). Estimation in the presence of stochastic parameter variation. Econometrica, 44, 167-84.

De Menil, G. and Bhalla, S. (1975). Direct measurement of popular price expectations. American Economic Review, 65, 169-80.

Defris, L. V. and Williams, R. A. (1979). Quantitative versus qualitative measures of price expectations. Economics Letters, 2, 169-73. 
Diebold, F. X. and Mariano, R. (1995). Comparing Predictive Accuracy. Journal of Business and Economic Statistics, 13, 253-63.

Easaw, J. Z. and Heravi, S. M. (2004). Evaluating Consumer Sentiments as Predictors of UK Household Consumption Behavior Are They Accurate and Useful?. International Journal of Forecasting, 20, 671-81.

Forsells, M. and Kenny, G. (2002). The Rationality of Consumer's Inflation Expectations: Surveybased evidence for the euro area. ECB Working Paper 163.

Garrett, T. A., Hernandez-Murillo, R. and Owyang, M. T. (2004). Does Consumer Sentiment Predict Regional Consumption?. Federal Reserve Bank of St. Louis Review, 87, 123-35

Grasmann, P. and Keereman, F. (2001). An indicator-based short-term forecast for quarterly GDP in the euro area. Economic Paper 154, European Commission.

Hamilton, J. (1989). A new approach to the economic analysis of nonstationary time series and the business cycle. Econometrica, 57, 357-384.

Hamilton, J. (1990). Analysis of time series subject to changes in regime. Journal of Econometrics, 45, 39-70.

Hansen, B., (1997). Inference in threshold models. Unpublished manuscript.

Harvey, A. (1982). The Kalman filter and its applications in Econometrics and time series analysis. Methods of Operational Research, 44, 3-18.

Harvey, A. (1987). Applications of the Kalman filter in Econometrics. In Bewley, T. (ed.), Advances in Econometrics: Fifth World Congress, Econometric Society Monograph 13. Cambridge University Press, Cambridge.

Howrey, E. P. (2001). The predictive power of the Index of Consumer Sentiment. Brookings Papers on Economic Activity, 1, 205-207. 
Kauppi, E., Lassila, J. and Terasvirta, T. (1996). Short-Term forecasting of industrial production with business survey data: experience from Finland's great depression 1990-1993. International Journal of Forecasting, 12, 373-381.

Kim, C. J. (1994). Dynamic Linear Models with Markov-Switching. Journal of Econometrics, 60, $1-22$.

Papadia, F. (1983). Inflationary Expectations in the European Economic Communities Countries. Empirical Economics, 8, 187-202.

Pesaran, M. H. (1987). The Limits to Rational Expectations. Basil Blackwell, Oxford.

Potter, S. (1999). Nonlinear Time Series Modelling: An Introduction. Federal Reserve Bank of New York, mimeo.

Seitz, H. (1988). The estimation of inflation forecasts from business survey data. Applied Economics, 20, 427-438.

Sédillot, F. and Pain, N. (2003). Indicators models of real GDP growth in selected OECD countries. ECO Working Paper 364.

Souleles, N. S. (2004). Expectations, Heterogeneous Forecast Errors, and Consumption: Micro Evidence from the Michigan Consumer Sentiment Surveys. Journal of Money, Credit, and Banking, $36,39-72$

Theil, H. (1952). On the time shape of economic microvariables and the Munich business test. Revue de l'Institut International de Statistique, 20, 105-120.

Theil, H. (1955). Recent experiences with the Munich business test: an expository article. Econometrica, 23, 184-192.

Vuchelen, J. (2004). Consumer Sentiment and Macroeconomic Forecasts. Journal of Economic Psychology, 25, 493-506 
Zimmermann, K. F. (1999). Analysis of Business Surveys. In Pesaran, M. H. and Schmidt, P. (Eds.), Handbook of Applied Econometrics. Volume II: Microeconomics. Blackwell Publishers, Oxford. 


\section{Endnotes}

1 Data used in this paper was obtained from the European Commission DG ECFIN website http://europa.eu.int/comm/economy finance/indicators/business consumer surveys/bcsseries en.ht $\underline{\mathrm{m}}$ ) in March 2006.

2 Data used in this paper was obtained from the Eurostat website (http://europa.eu.int/comm/eurostat) and the ECB website (http://www.ecb.int) in March 2006.

${ }^{3}$ The Hamilton filter is an iterative procedure which provides estimates of the probability that a given state is prevailing at each point in time given its previous history. These estimates are dependent upon the parameter values given to the filter. Running the filter through the entire sample, provides a log likelihood value for the particular set of estimates used. This filter is then repeated to optimise the log likelihood to obtain the MLE estimates of the parameters. With the maximum likelihood parameters, the probability of state 0 at each point in time is calculated and these are the probabilities of recession and expansion.

${ }^{4}$ An alternative approach would have consisted in imposing the value of $\mathrm{P}$ and $\mathrm{k}$ instead of estimating them. These models are known as Markov Switching Autoregressive Models (MS-AR) and, in general, the values of $\mathrm{P}$ are 0.7 or 0.8 and the values of $\mathrm{k}, 0$ or 1 .

${ }^{5}$ We are grateful to an anonymous referee for this suggestion.

${ }^{6}$ This measure has been calculated using the Stata routine by Christopher F. Baum which is available at http://fmwww.bc.edu/repec/bocode/d/dmariano.ado and http://fmwww.bc.edu/repec/bocode/d/dmariano.hlp.

${ }^{7}$ We have carried out similar analysis for different periods and results have been similar. For example, using information up to 2000.12 or 2000.IV for estimating the model and forecasts until 2001.12 or $2001 . I V$, in 12 out of 19 cases there is no significant difference between forecasts including survey information or not. However, in seven cases the difference is significant and in five of them, this difference is in favour of models with survey information. 
${ }^{8}$ To our knowledge, no other study covers such a high number of macroeconomic variables and indicators (attention has been usually paid to industrial production, inflation and GDP). The number of econometric methods and models applied is also considerable higher than in previous research.

${ }^{9}$ Among others, it is worth mentioning the works by Easaw and Heravi (2004), Garret et al. (2004), Souleles (2004), Vuchelen (2004) for consumption, Kauppi et al. (1996) and Bodo et al. (2000) for industrial production, Howrey (2001) and Forsells and Kenny (2002) for inflation, Sédillot and Pain (2003) for GDP and the more broad works by the European Commission (the BUSY and BUSY II models or the approach by Grasmann and Keereman, 2001) or by the European Central Bank . 
Table 1. List of business and consumer surveys indicators for the euro area (continues next page)

\begin{tabular}{|c|c|c|c|c|c|c|c|c|c|c|c|}
\hline \multirow{2}{*}{ v1 } & \multirow{2}{*}{$\begin{array}{l}\text { Description } \\
\text { Economic Sentiment Indicator }\end{array}$} & \multirow{2}{*}{$\begin{array}{l}\text { Freq. } \\
\text { month }\end{array}$} & \multicolumn{2}{|c|}{ Sample } & \multirow{2}{*}{ Obs. } & \multicolumn{6}{|c|}{ Categories } \\
\hline & & & jan-85 & dec-05 & & & & & & & \\
\hline v2 & Industrial Confidence Indicator $(\mathrm{v} 7+\mathrm{v} 4-\mathrm{v} 6) / 3$ & month & jan-85 & dec-05 & 252 & & & & & & \\
\hline v3 & Production trend observed in recent months & month & jan-85 & dec-05 & 252 & $\mathrm{P}$ & E & $\mathrm{M}$ & & & $\mathrm{B}$ \\
\hline v4 & Assessment of order-book levels & month & jan-85 & dec-05 & 252 & $\mathrm{P}$ & E & $\mathrm{M}$ & & & $\mathrm{B}$ \\
\hline v5 & Assessment of export order-book levels & month & jan-85 & dec-05 & 252 & $\mathrm{P}$ & E & $\mathrm{M}$ & & & $\mathrm{B}$ \\
\hline v6 & Assessment of stocks of finished products & month & jan-85 & dec-05 & 252 & $\mathrm{P}$ & E & $\mathrm{M}$ & & & $\mathrm{B}$ \\
\hline v7 & Production expectations for the months ahead & month & jan-85 & dec-05 & 252 & $\mathrm{P}$ & E & $\mathrm{M}$ & & & $\mathrm{B}$ \\
\hline $\mathrm{v} 8$ & Selling price expectations for the months ahead & month & jan-85 & dec-05 & 252 & $\mathrm{P}$ & E & $\mathrm{M}$ & & & $\mathrm{B}$ \\
\hline v9 & Employment expectations for the months ahead & month & jan-85 & dec-05 & 252 & $\mathrm{P}$ & E & $\mathrm{M}$ & & & $\mathrm{B}$ \\
\hline $\mathrm{v} 10$ & New orders in recent months & quarter & $1985-\mathrm{I}$ & 2005-IV & 84 & $\mathrm{P}$ & E & $\mathrm{M}$ & & & $\mathrm{B}$ \\
\hline v11 & Export expectations for the months ahead & quarter & $1985-\mathrm{I}$ & 2005-IV & 84 & $\mathrm{P}$ & E & $\mathrm{M}$ & & & $\mathrm{B}$ \\
\hline v12 & Consumer Confidence Indicator (v14+v16-v19+v23)/4 & month & jan-85 & dec-05 & 252 & & & & & & \\
\hline $\mathrm{v} 13$ & Financial situation over last 12 months & month & jan-85 & dec-05 & 252 & PP & $\mathrm{P}$ & E & $\mathrm{M}$ & MM & $\mathrm{N} \mathrm{B}$ \\
\hline v14 & Financial situation over next 12 months & month & jan-85 & dec-05 & 252 & $\mathrm{PP}$ & $\mathrm{P}$ & E & $\mathrm{M}$ & MM & $\mathrm{N} \mathrm{B}$ \\
\hline v15 & General economic situation over last 12 months & month & jan-85 & dec-05 & 252 & PP & $\mathrm{P}$ & E & $\mathrm{M}$ & MM & $\mathrm{N} \mathrm{B}$ \\
\hline $\mathrm{v} 16$ & General economic situation over next 12 months & month & jan-85 & dec-05 & 252 & PP & $\mathrm{P}$ & E & $\mathrm{M}$ & MM & $\mathrm{N} \mathrm{B}$ \\
\hline v17 & Price trends over last 12 months & month & jan-85 & dec-05 & 252 & PP & $\mathrm{P}$ & E & $\mathrm{M}$ & MM & $\mathrm{N} \mathrm{B}$ \\
\hline $\mathrm{v} 18$ & Price trends over next 12 months & month & jan-85 & dec-05 & 252 & $\mathrm{PP}$ & $\mathrm{P}$ & E & $\mathrm{M}$ & MM & $\mathrm{N} \mathrm{B}$ \\
\hline v19 & Unemployment expectations over next 12 months & month & jan-85 & dec-05 & 252 & PP & $\mathrm{P}$ & $\mathrm{E}$ & $\mathrm{M}$ & MM & $\mathrm{N} \mathrm{B}$ \\
\hline $\mathrm{v} 20$ & Major purchases at present & month & jan-85 & dec-05 & 252 & PP & $\mathrm{E}$ & MM & $\mathrm{N}$ & & $\mathrm{B}$ \\
\hline $\mathrm{v} 21$ & Major purchases over next 12 months & month & jan-85 & dec-05 & 252 & $\mathrm{PP}$ & $\mathrm{P}$ & $\mathrm{E}$ & $\mathrm{M}$ & MM & $\mathrm{NB}$ \\
\hline $\mathrm{v} 22$ & Savings at present & month & jan-85 & dec-05 & 252 & $\mathrm{PP}$ & $\mathrm{P}$ & $\mathrm{M}$ & $\mathrm{MM}$ & $\mathrm{N}$ & $\mathrm{B}$ \\
\hline $\mathrm{v} 23$ & Savings over next 12 months & month & jan-85 & dec-05 & 252 & PP & $\mathrm{P}$ & $\mathrm{M}$ & MM & $\mathrm{N}$ & $\mathrm{B}$ \\
\hline $\mathrm{v} 24$ & Statement on financial situation of household & month & jan-85 & dec-05 & 252 & PP & $\mathrm{P}$ & E & $\mathrm{M}$ & MM & $\mathrm{N} \mathrm{B}$ \\
\hline $\mathrm{v} 25$ & Intention to buy a car within the next 2 years & quarter & 1990-I & 2005-IV & 64 & $\mathrm{PP}$ & $\mathrm{P}$ & $\mathrm{M}$ & MM & $\mathrm{N}$ & $\mathrm{B}$ \\
\hline $\mathrm{v} 26$ & Purchase or build a home within the next 2 years & quarter & 1990-I & 2005-IV & 64 & PP & $\mathrm{P}$ & $\mathrm{M}$ & MM & $\mathrm{N}$ & $\mathrm{B}$ \\
\hline $\mathrm{v} 27$ & Home improvements over the next 12 months & quarter & 1990-I & 2005-IV & 64 & PP & $\mathrm{P}$ & $\mathrm{M}$ & MM & $\mathrm{N}$ & $\mathrm{B}$ \\
\hline
\end{tabular}




\section{Table 1. List of business and consumer surveys indicators for the euro area (continuation)}

\begin{tabular}{|c|c|c|c|c|c|c|c|c|c|}
\hline \multirow[b]{2}{*}{ v28 } & \multirow{2}{*}{$\begin{array}{l}\text { Description } \\
\text { Construction Confidence Indicator }(\mathrm{v} 30+v 31) / 2\end{array}$} & \multirow{2}{*}{$\begin{array}{l}\text { Freq. } \\
\text { month }\end{array}$} & \multicolumn{2}{|c|}{ Sample } & \multirow{2}{*}{ Obs } & \multicolumn{4}{|c|}{ Categories } \\
\hline & & & jan-85 & dec-05 & & & & & \\
\hline v29 & Trend of activity compared with preceding months & month & jan-85 & dec-05 & 252 & $\mathrm{P}$ & $\mathrm{E}$ & $\mathrm{M}$ & $\mathrm{B}$ \\
\hline v30 & Assessment of order books & month & jan-85 & dec-05 & 252 & $\mathrm{P}$ & E & $\mathrm{M}$ & $\mathrm{B}$ \\
\hline v31 & Employment expectations for the months ahead & month & jan-85 & dec-05 & 252 & $\mathrm{P}$ & E & $\mathrm{M}$ & $\mathrm{B}$ \\
\hline $\mathrm{v} 32$ & Price expectations for the months ahead & month & jan-85 & dec-05 & 252 & $\mathrm{P}$ & $\mathrm{E}$ & $\mathrm{M}$ & $\mathrm{B}$ \\
\hline v33 & Retail Trade Confidence Indicator (v34-v35+v37)/3 & month & jan-86 & dec-05 & 240 & & & & \\
\hline v34 & Present business situation & month & jan-85 & dec-05 & 252 & $\mathrm{P}$ & $\mathrm{E}$ & $\mathrm{M}$ & $\mathrm{B}$ \\
\hline $\mathrm{v} 35$ & Assessment of stocks & month & jan-85 & dec-05 & 252 & $\mathrm{P}$ & E & $\mathrm{M}$ & $\mathrm{B}$ \\
\hline v36 & Orders placed with suppliers & month & feb-85 & dec-05 & 251 & $\mathrm{P}$ & $\mathrm{E}$ & $\mathrm{M}$ & $\mathrm{B}$ \\
\hline v37 & Expected business situation & month & jan-86 & dec-05 & 240 & $\mathrm{P}$ & $\mathrm{E}$ & $\mathrm{M}$ & $\mathrm{B}$ \\
\hline v38 & Employment & month & abr-85 & dec-05 & 249 & $\mathrm{P}$ & E & $\mathrm{M}$ & $\mathrm{B}$ \\
\hline v39 & Services Confidence Indicator $(\mathrm{v} 40+\mathrm{v} 41+\mathrm{v} 42) / 3$ & month & abr-95 & dec-05 & 129 & & & & \\
\hline $\mathrm{v} 40$ & Assessment of business climate & month & abr-95 & dec-05 & 129 & $\mathrm{P}$ & $\mathrm{E}$ & $\mathrm{M}$ & $\mathrm{B}$ \\
\hline $\mathrm{v} 41$ & Evolution of demand in recent months & month & abr-95 & dec-05 & 129 & $\mathrm{P}$ & $\mathrm{E}$ & $\mathrm{M}$ & $\mathrm{B}$ \\
\hline $\mathrm{v} 42$ & Evolution of demand expected in the months ahead & month & abr-95 & dec-05 & 129 & $\mathrm{P}$ & E & $\mathrm{M}$ & $\mathrm{B}$ \\
\hline $\mathrm{v} 43$ & Evolution of employment in recent months & month & abr-95 & dec-05 & 129 & $\mathrm{P}$ & E & $\mathrm{M}$ & $\mathrm{B}$ \\
\hline $\mathrm{v} 44$ & Evolution of employment expected in the months ahead & month & jan-97 & dec-05 & 108 & $\mathrm{P}$ & E & $\mathrm{M}$ & $\mathrm{B}$ \\
\hline
\end{tabular}

The letters refer to positive answers (pp and p), neutral answers (e), negative answers (mm and m), non answers (n), balance (b) and composite indicators (i). 


\section{Table 2. List of considered macroeconomic variables}

\section{Endogenous variables}

\begin{tabular}{|c|c|c|c|c|c|}
\hline \multirow[b]{2}{*}{ qv1 } & \multirow{2}{*}{$\begin{array}{l}\text { Description } \\
\text { Harmonized consumer price index }\end{array}$} & \multirow{2}{*}{$\begin{array}{c}\text { Freq. } \\
\text { Monthly }\end{array}$} & \multicolumn{2}{|c|}{ sample } & \multirow{2}{*}{$\begin{array}{c}\text { Obs } \\
192 \\
\end{array}$} \\
\hline & & & jan-90 & dec-05 & \\
\hline qv2 & Construction - number of persons employed index & Monthly & jan-91 & dec-05 & 180 \\
\hline qv3 & Building permits index - New residential buildings & Monthly & jan-85 & nov-05 & 251 \\
\hline qv4 & Industry Production index & Monthly & jan-85 & dec-05 & 252 \\
\hline qv5 & Industry Producer price index & Monthly & jan-85 & dec- -05 & 252 \\
\hline qv6 & Number of new car registrations & Monthly & jan-85 & dec-05 & 252 \\
\hline qv7 & Retail Deflated turnover index & Monthly & jan-94 & dec-05 & 144 \\
\hline qv8 & Unemployment rate & Monthly & jan-93 & dec- -05 & 156 \\
\hline qv9 & Industry Gross value added & Quarterly & 1991-I & 2005-IV & 60 \\
\hline $\mathrm{qv} 10$ & Construction Gross value added & Quarterly & 1991-I & 2005-IV & 60 \\
\hline qv11 & Wholesale and retail trade $\&$ other Gross value added & Quarterly & 1991-I & 2005-IV & 60 \\
\hline qv12 & Financial intermediation Gross value added & Quarterly & 1991-I & 2005-IV & 60 \\
\hline qv13 & Savings rate & Quarterly & 1991-I & 2005-III & 59 \\
\hline qv14 & Gross domestic product & Quarterly & 1991-I & 2005-IV & 60 \\
\hline qv15 & Gross fixed capital formation: construction work - other constructions & Quarterly & 1991-I & 2005-III & 59 \\
\hline qv16 & Gross fixed capital formation: metal products and machinery & Quarterly & 1991-I & 2005-III & 59 \\
\hline qv17 & Exports of goods & Quarterly & 1991-I & 2005-IV & 60 \\
\hline qv18 & Final consumption expenditure: household and NPISH & Quarterly & 1991-I & 2005-IV & 60 \\
\hline qv19 & Gross fixed capital formation: construction work - housing & Quarterly & 1991-I & 2005-III & 69 \\
\hline
\end{tabular}

\section{Exogenous variables}

\begin{tabular}{|c|c|c|c|c|c|}
\hline & Description & Freq. & \multicolumn{2}{|c|}{ Sample } & Obs \\
\hline qv20 & Interest rate & Quarterly & 1990-I & 2005-IV & 64 \\
\hline qv21 & Exchange rate & Quarterly & 1993-I & 2005-IV & 52 \\
\hline
\end{tabular}


Table 3 Correspondence between business and consumer surveys indicators and the selected macroeconomic variables (continues)

Description

\begin{tabular}{|c|c|c|c|c|c|}
\hline v1 & Economic Sentiment Indicator & qv13 & & & \\
\hline v2 & Industrial Confidence Indicator $(v 7+v 4-v 6) / 3$ & & & & \\
\hline v3 & Production trend observed in recent months & qv4 & qv8 & qv13 & \\
\hline $\mathrm{v} 4$ & Assessment of order-book levels & qv4 & qv8 & qv13 & \\
\hline v5 & Assessment of export order-book levels & qv4 & qv8 & qv13 & qv16 \\
\hline v6 & Assessment of stocks of finished products & qv4 & qv8 & qv13 & \\
\hline $\mathrm{v} 7$ & Production expectations for the months ahead & qv4 & qv8 & qv13 & \\
\hline v8 & Selling price expectations for the months ahead & qv1 & qv5 & & \\
\hline v9 & Employment expectations for the months ahead & qv4 & qv8 & qv13 & qv19 \\
\hline $\mathrm{v} 10$ & New orders in recent months & qv4 & qv8 & qv15 & \\
\hline v11 & Export expectations for the months ahead & qv4 & qv8 & qv13 & qv16 \\
\hline v12 & Consumer Confidence Indicator (v14+v16-v19+v23)/4 & qv13 & qv17 & & \\
\hline v13 & Financial situation over last 12 months & qv6 & qv13 & qv17 & \\
\hline v14 & Financial situation over next 12 months & qv6 & qv13 & qv17 & \\
\hline $\mathrm{v} 15$ & General economic situation over last 12 months & qv6 & qv13 & qv17 & \\
\hline $\mathrm{v} 16$ & General economic situation over next 12 months & qv6 & qv13 & qv17 & \\
\hline $\mathrm{v} 17$ & Price trends over last 12 months & qv1 & & & \\
\hline v18 & Price trends over next 12 months & qv1 & & & \\
\hline v19 & Unemployment expectations over next 12 months & qv13 & qv17 & qv19 & \\
\hline $\mathrm{v} 20$ & Major purchases at present & qv13 & qv17 & & \\
\hline v21 & Major purchases over next 12 months & qv13 & qv17 & & \\
\hline $\mathrm{v} 22$ & Savings at present & qv12 & & & \\
\hline v23 & Savings over next 12 months & qv12 & & & \\
\hline v24 & Statement on financial situation of household & qv12 & & & \\
\hline $\mathrm{v} 25$ & Intention to buy a car within the next 2 years & qv6 & & & \\
\hline $\mathrm{v} 26$ & Purchase or build a home within the next 2 years & qv18 & & & \\
\hline v27 & Home improvements over the next 12 months & qv18 & & & \\
\hline
\end{tabular}


Table 3 Correspondence between business and consumer surveys indicators and the selected macroeconomic variables (continuation)

\section{Description}

\begin{tabular}{|c|c|c|c|c|c|c|}
\hline v28 & Construction Confidence Indicator $(\mathrm{v} 30+\mathrm{v} 31) / 2$ & qv3 & qv10 & qv14 & qv15 & qv19 \\
\hline $\mathrm{v} 29$ & Trend of activitiy compared with preceding months & qv3 & qv10 & qv14 & qv15 & qv19 \\
\hline $\mathrm{v} 30$ & Assessment of order books & qv3 & qv10 & qv14 & qv15 & qv19 \\
\hline $\mathrm{v} 31$ & Employment expectations for the months ahead & qv2 & qv8 & & & \\
\hline $\mathrm{v} 32$ & Price expectations for the months ahead & qv1 & & & & \\
\hline v33 & Retail Trade Confidence Indicator (v34-v35+v37)/3 & qv11 & qv14 & & & \\
\hline v34 & Present business situation & qv11 & qv14 & & & \\
\hline $\mathrm{v} 35$ & Assessment of stocks & qv11 & & & & \\
\hline $\mathrm{v} 36$ & Orders placed with suppliers & qv11 & & & & \\
\hline v37 & Expected business situation & qv11 & qv14 & & & \\
\hline $\mathrm{v} 38$ & Employment & qv8 & & & & \\
\hline v39 & Services Confidence Indicator $(v 40+v 41+v 42) / 3$ & qv11 & qv12 & qv14 & & \\
\hline $\mathrm{v} 40$ & Assessment of business climate & qv11 & qv12 & qv14 & & \\
\hline $\mathrm{v} 41$ & Evolution of demand in recent months & qv11 & qv12 & qv14 & & \\
\hline $\mathrm{v} 42$ & Evolution of demand expected in the months ahead & qv11 & qv12 & qv14 & & \\
\hline $\mathrm{v} 43$ & Evolution of employment in recent months & qv8 & & & & \\
\hline v44 & Evolution of employment expected in the months ahead & qv8 & & & & \\
\hline
\end{tabular}


Table 4. VAR models specification

\begin{tabular}{|l|l|}
\hline VAR model & Considered quantitative variables \\
\hline Total of the economy & $\begin{array}{l}\text { Harmonized consumer price index } \\
\text { Gross domestic product } \\
\text { Unemployment rate }\end{array}$ \\
\hline Supply & $\begin{array}{l}\text { Industry Gross value added } \\
\text { Construction Gross value added } \\
\text { Wholesale and retail trade \& other Gross value added } \\
\text { Financial intermediation Gross value added }\end{array}$ \\
\hline Industry (a) & $\begin{array}{l}\text { Industry Production index } \\
\text { Industry Producer price index }\end{array}$ \\
\hline Industry (b) & $\begin{array}{l}\text { Industry Production index } \\
\text { Industry Producer price index } \\
\text { Gross fixed capital formation: metal products and machinery }\end{array}$ \\
\hline Building & $\begin{array}{l}\text { Construction - number of persons employed index } \\
\text { Building permits index - New residential buildings } \\
\text { Gross fixed capital formation: construction work - other constructions } \\
\text { Gross fixed capital formation: construction work - housing } \\
\text { Interest rates }\end{array}$ \\
\hline Exports & $\begin{array}{l}\text { Gross domestic product } \\
\text { Exports of goods } \\
\text { Exchange rates }\end{array}$ \\
\hline Consumption & $\begin{array}{l}\text { Harmonized consumer price index } \\
\text { Gross domestic product } \\
\text { Final consumption expenditure: household and NPISH } \\
\text { Unemployment rate } \\
\text { Interest rates }\end{array}$ \\
\hline Savings & $\begin{array}{l}\text { Harmonized consumer price index } \\
\text { Savings rate } \\
\text { Gross domestic product } \\
\text { Interest rates }\end{array}$ \\
\hline
\end{tabular}

\section{Table 5. Specification of "augmented" VAR models}

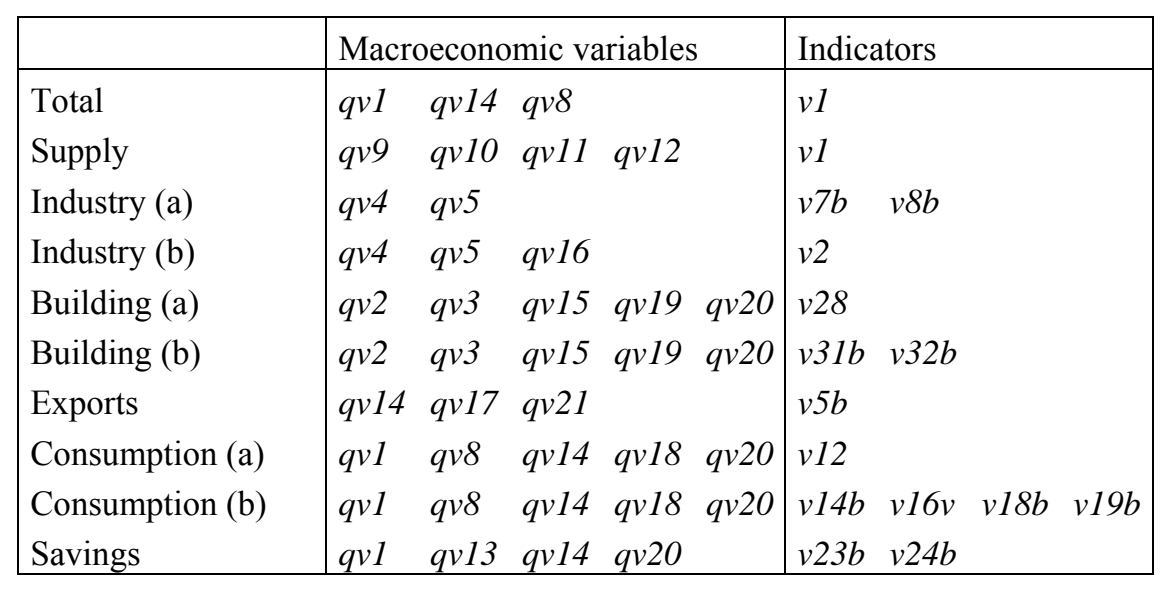


Table 6. Summary of the results of the Kruskal Wallis test

\begin{tabular}{cccc}
\hline & Rejection of the Null & Non-rejection of the Null & TOTAL \\
\hline Month & 9 & 30 & 39 \\
Quarter & 1 & 4 & 5 \\
\hline TOTAL & 10 & 34 & 44 \\
\hline \multicolumn{5}{c}{} & & \\
\hline Month & Rejection of the Null & Non-rejection of the Null & TOTAL \\
Quarter & $23.08 \%$ & $76.92 \%$ & $100.00 \%$ \\
\hline TOTAL & $20.00 \%$ & $80.00 \%$ & $100.00 \%$ \\
\hline
\end{tabular}

Null hypothesis: Non-seasonal pattern in the considered serie

Table 7. Summary of the results from the forecasting competition

Monthly models

\begin{tabular}{|c|c|c|c|c|c|c|}
\hline & & 1 month & 2 months & 3 months & 6 months & 12 months \\
\hline \multirow{5}{*}{$\begin{array}{l}\grave{D} \\
\grave{Z} \\
0 \\
\stackrel{0}{0} \\
z\end{array}$} & $\mathrm{AR}$ & $\begin{array}{l}\text { qv1, qv3, qv5, } \\
\text { qv6, qv7, qv8 }\end{array}$ & $\begin{array}{c}\text { qv1, qv3, qv5 } \\
\text { qv7, qv8 }\end{array}$ & $\begin{array}{l}\text { qv1, qv3, qv5, } \\
\text { qv6, qv7, qv8 }\end{array}$ & qv1, qv6, qv7 & qv1 \\
\hline & ARIMA & & & & & \\
\hline & TAR & & & & & \\
\hline & MK-TAR & & & & & \\
\hline & VAR & & & & & \\
\hline \multirow{4}{*}{$\stackrel{\vec{D}}{\stackrel{\vec{\omega}}{\Rightarrow}}$} & $\mathrm{AR}$ & qv4 & qv4 & qv4 & qv4 & qv7, qv8 \\
\hline & MK-TAR & & & & & \\
\hline & VAR & & & & & qv4 \\
\hline & Leading indicator & qv2 & qv2, qv6 & qv2 & $\begin{array}{l}\text { qv2, qv3, } \\
\text { qv5, qv8 }\end{array}$ & $\begin{array}{l}\text { qv2, qv3, } \\
\text { qv5, qv6 }\end{array}$ \\
\hline
\end{tabular}

Quarterly models

\begin{tabular}{|c|c|c|c|c|}
\hline & & 1 quarter & 2 quarters & 4 quarters \\
\hline \multirow{5}{*}{ 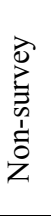 } & $\mathrm{AR}$ & qv10 & qv10 & \\
\hline & ARIMA & & & \\
\hline & TAR & & & \\
\hline & MK-TAR & & & qv9 \\
\hline & VAR & qv14, qv15, qv16, qv19 & qv15 & qv14, qv18 \\
\hline \multirow{4}{*}{ 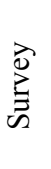 } & AR & & qv16 & qv10, qv17 \\
\hline & MK-TAR & qv9 & qv9 & \\
\hline & Leading indicator & qv11, qv13, qv17, qv18, qv19 & qv13, qv14, qv17, qv18, qv19 & qv12, qv13 \\
\hline & VAR & qv12 & qv11, qv12 & qv11, qv15, qv16 \\
\hline
\end{tabular}


Table 8. Results of the Diebold-Mariano test

\begin{tabular}{cccc} 
Monthly data: $2002 \mathrm{~m} 1-2002 \mathrm{~m} 12$ & \multicolumn{2}{c}{ Quarterly data: 2002q1-2002q4 } \\
\hline qv1 & -1.26 & qv9 & -0.12 \\
qv2 & $-2.24^{*}$ & qv10 & -1.92 \\
qv3 & 0.29 & qv11 & -0.01 \\
qv4 & -1.72 & qv12 & 1.02 \\
qv5 & $-3.81^{*}$ & qv13 & $\mathbf{3 . 8 4 *}$ \\
qv6 & $\mathbf{3 . 8 1 *}$ & qv14 & $-2.18^{*}$ \\
qv7 & $\mathbf{2 . 9 7 *}$ & qv15 & $\mathbf{3 . 1 4 *}$ \\
qv8 & $\mathbf{2 . 6 4 *}$ & qv16 & $-2.45^{*}$ \\
& & qv17 & -1.49 \\
& & qv18 & -1.67 \\
& & qv19 & $-10.88^{*}$
\end{tabular}

Null hypothesis: The difference between the two competing series is non-significant.

A positive sign of the statistic implies that the RMSE associated to the forecast from the model with survey information is lower while a negative sign implies the opposite.

* significant at the $5 \%$ level. 
Figure 1. Comparison of actual values and significantly different competing forecasts according to the Diebold-Mariano test
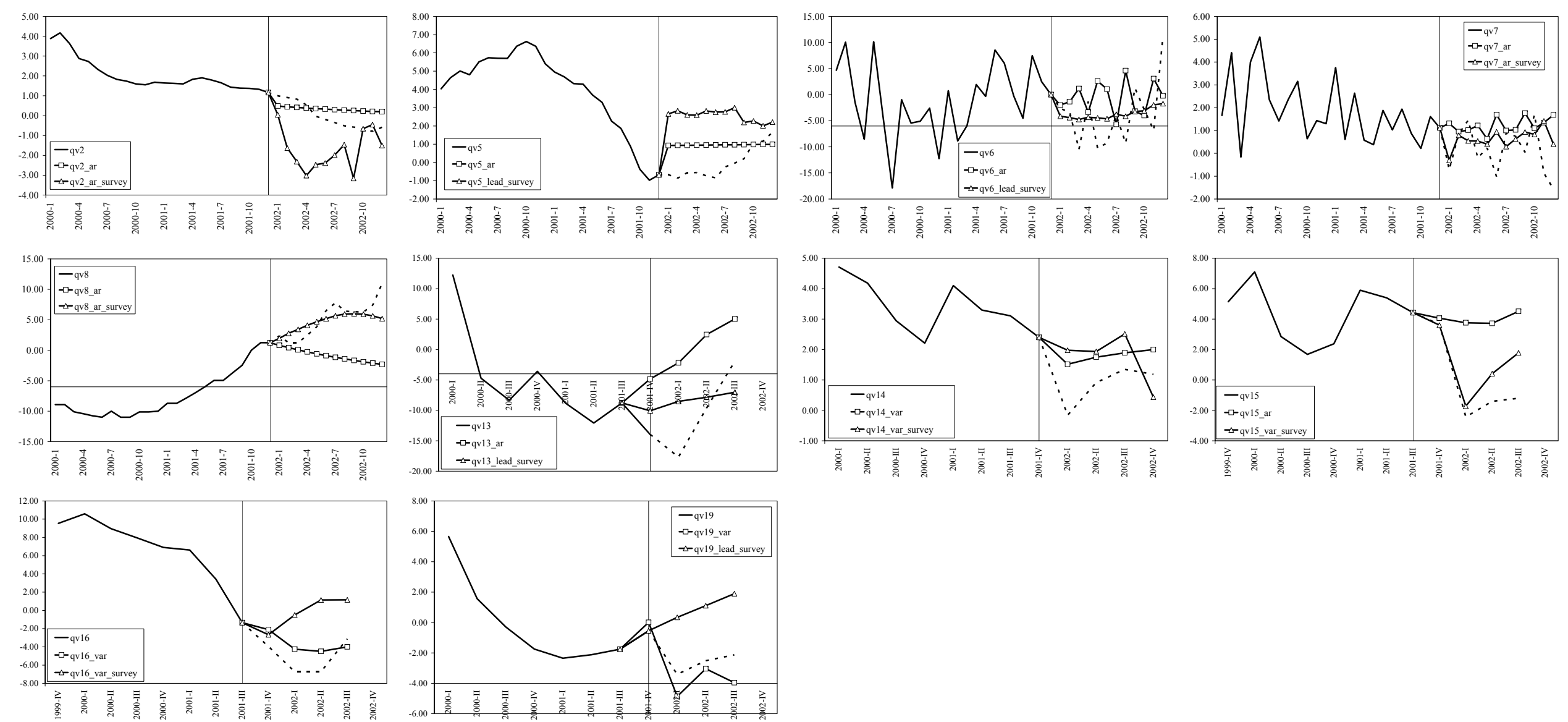
Appendix A.

Table A.1. Detailed results of the Kruskal-Wallis test

\begin{tabular}{|c|c|c|c|}
\hline Variable & KW-statistic & P-value & \\
\hline v1 & 6.04 & 0.87 & Non RH0 \\
\hline $\mathrm{v} 2$ & 8.26 & 0.69 & Non RH0 \\
\hline $\mathrm{v} 3 \mathrm{~b}$ & 29.23 & 0.00 & RH0 \\
\hline $\mathrm{v} 4 \mathrm{~b}$ & 1.84 & 1.00 & Non RH0 \\
\hline $\mathrm{v} 5 \mathrm{~b}$ & 1.59 & 1.00 & Non RH0 \\
\hline $\mathrm{v} 6 \mathrm{~b}$ & 4.74 & 0.94 & Non RH0 \\
\hline $\mathrm{v} 7 \mathrm{~b}$ & 73.50 & 0.00 & RHO \\
\hline $\mathrm{v} 8 \mathrm{~b}$ & 25.06 & 0.01 & RHO \\
\hline $\mathrm{v} 9 \mathrm{~b}$ & 5.16 & 0.92 & Non RH0 \\
\hline $\mathrm{v} 10 \mathrm{~b}$ & 14.06 & 0.00 & RHO \\
\hline v11b & 5.67 & 0.13 & Non RH0 \\
\hline v12 & 5.85 & 0.88 & Non RH0 \\
\hline $\mathrm{v} 13 \mathrm{~b}$ & 1.53 & 1.00 & Non RH0 \\
\hline $\mathrm{v} 14 \mathrm{~b}$ & 4.25 & 0.96 & Non RH0 \\
\hline $\mathrm{v} 15 \mathrm{~b}$ & 1.27 & 1.00 & Non RH0 \\
\hline $\mathrm{v} 16 \mathrm{~b}$ & 8.13 & 0.70 & Non RH0 \\
\hline $\mathrm{v} 17 \mathrm{~b}$ & 0.43 & 1.00 & Non RH0 \\
\hline $\mathrm{v} 18 \mathrm{~b}$ & 2.46 & 1.00 & Non RH0 \\
\hline $\mathrm{v} 19 \mathrm{~b}$ & 7.34 & 0.77 & Non RH0 \\
\hline $\mathrm{v} 20 \mathrm{~b}$ & 4.11 & 0.97 & Non RH0 \\
\hline $\mathrm{v} 21 \mathrm{~b}$ & 1.10 & 1.00 & Non RH0 \\
\hline $\mathrm{v} 22 \mathrm{~b}$ & 1.06 & 1.00 & Non RH0 \\
\hline $\mathrm{v} 23 \mathrm{~b}$ & 4.73 & 0.94 & Non RH0 \\
\hline $\mathrm{v} 24 \mathrm{~b}$ & 2.10 & 1.00 & Non RH0 \\
\hline $\mathrm{v} 25 \mathrm{~b}$ & 0.88 & 0.83 & Non RH0 \\
\hline $\mathrm{v} 26 \mathrm{~b}$ & 0.27 & 0.97 & Non RH0 \\
\hline $\mathrm{v} 27 \mathrm{~b}$ & 0.38 & 0.94 & Non RH0 \\
\hline v28 & 27.01 & 0.00 & RHO \\
\hline $\mathrm{v} 29 \mathrm{~b}$ & 150.68 & 0.00 & RH0 \\
\hline $\mathrm{v} 30 \mathrm{~b}$ & 14.52 & 0.21 & Non RH0 \\
\hline v31b & 70.02 & 0.00 & RHO \\
\hline $\mathrm{v} 32 \mathrm{~b}$ & 9.81 & 0.55 & Non RH0 \\
\hline v33 & 7.45 & 0.76 & Non RH0 \\
\hline $\mathrm{v} 34 \mathrm{~b}$ & 1.91 & 1.00 & Non RH0 \\
\hline $\mathrm{v} 35 \mathrm{~b}$ & 48.11 & 0.00 & RH0 \\
\hline v36b & 21.40 & 0.03 & RHO \\
\hline v37b & 9.42 & 0.58 & Non RH0 \\
\hline $\mathrm{v} 38 \mathrm{~b}$ & 34.70 & 0.00 & RHO \\
\hline v39 & 0.88 & 1.00 & Non RH0 \\
\hline $\mathrm{v} 40 \mathrm{~b}$ & 0.39 & 1.00 & Non RH0 \\
\hline $\mathrm{v} 41 \mathrm{~b}$ & 7.94 & 0.72 & Non RH0 \\
\hline $\mathrm{v} 42 \mathrm{~b}$ & 7.53 & 0.75 & Non RH0 \\
\hline $\mathrm{v} 43 \mathrm{~b}$ & 3.90 & 0.97 & Non RH0 \\
\hline $\mathrm{v} 44 \mathrm{~b}$ & 14.62 & 0.20 & Non RH0 \\
\hline
\end{tabular}

H0: Non-seasonality / HA: seasonality 


\section{Appendix B.}

\section{Table B.1}

qv1: HCPI. Year-on-year growth rates of raw data

Average RMSE - Recursive forecasts from January 2002 to December 2005

\begin{tabular}{|c|c|c|c|c|c|}
\hline Models without survey information & 1 month & 2 months & 3 months & 6 months & 12 months \\
\hline AR & $0.20 *$ & $0.26^{*}$ & $0.30 *$ & $0.30 *$ & $0.28 *$ \\
\hline ARIMA & 1.55 & 1.85 & 2.18 & 2.32 & 2.53 \\
\hline TAR & 2.04 & 3.12 & 3.91 & 6.03 & 13.13 \\
\hline Models with survey information & 1 month & 2 months & 3 months & 6 months & 12 months \\
\hline $\mathrm{AR}(+\mathrm{v} 18 \mathrm{~b})$ & 0.20 & 0.26 & 0.33 & 0.41 & 0.58 \\
\hline AR (+v18 quantified) & 0.20 & 0.27 & 0.34 & 0.41 & 0.57 \\
\hline Leading indicators model 1 & 0.56 & 0.55 & 0.66 & 0.43 & 0.52 \\
\hline Leading indicators model 2 & 0.42 & 0.37 & 0.43 & 0.53 & 0.82 \\
\hline
\end{tabular}

v18: Price trends over next 12 months

b: balance

Italics: best model without survey information

Bold: Better forecast performance than best model without survey information

* Best model 


\section{Table B.2}

qv2. Construction - number of persons employed index: Year-on-year growth rates of raw data Average RMSE - Recursive forecasts from January 2002 to December 2005

\begin{tabular}{|c|c|c|c|c|c|}
\hline Models without survey information & 1 month & 2 months & 3 months & 6 months & 12 months \\
\hline $\mathrm{AR}$ & 0.78 & 0.95 & 1.10 & 1.32 & 1.38 \\
\hline ARIMA & 6.19 & 7.93 & 8.75 & 10.14 & 10.66 \\
\hline TAR & 25.89 & 26.49 & 52.13 & 230.52 & 1102.48 \\
\hline MK-TAR & 0.99 & 1.35 & 9.25 & 52.58 & 10.76 \\
\hline Models with survey information & 1 month & 2 month & 3 month & 6 months & 12 months \\
\hline $\mathrm{AR}(+\mathrm{v} 31 \mathrm{~b})$ & 0.77 & 0.93 & 1.05 & 1.24 & 1.15 \\
\hline AR $(+v 31 b$ quantified $)$ & 0.77 & 0.93 & 1.06 & 1.27 & 1.22 \\
\hline Leading indicators model 1 & $0.42 *$ & $0.37 *$ & $0.43 *$ & $0.53 *$ & $0.82 *$ \\
\hline Leading indicators model 2 & 1.55 & 2.01 & 1.04 & 2.39 & 3.82 \\
\hline
\end{tabular}

v31: Employment expectations for the months ahead

b: balance

Italics: best model without survey information

Bold: Better forecast performance than best model without survey information

* Best model 


\section{Table B.3}

qv3: Building permits index. Year-on-year growth rates of raw data

Average RMSE - Recursive forecasts from December 2001 to November 2005

\begin{tabular}{|c|c|c|c|c|c|}
\hline Models without survey information & 1 month & 2 months & 3 months & 6 months & 12 months \\
\hline $\mathrm{AR}$ & $5.55^{*}$ & $5.92 *$ & $6.19 *$ & 7.04 & 6.48 \\
\hline ARIMA & 39.87 & 43.83 & 47.42 & 53.18 & 56.89 \\
\hline TAR & 68.87 & 97.78 & 125.16 & 172.36 & 261.11 \\
\hline MK-TAR & 6.47 & 7.98 & 8.98 & 10.20 & 7.83 \\
\hline Models with survey information & 1 month & 2 months & 3 months & 6 months & 12 months \\
\hline $\mathrm{AR}(+\mathrm{v} 29 \mathrm{~b})$ & 6.47 & 6.93 & 6.96 & 7.71 & 7.07 \\
\hline $\mathrm{AR}(+\mathrm{v} 30 \mathrm{~b})$ & 6.14 & 6.39 & 6.49 & 7.23 & 6.96 \\
\hline $\mathrm{AR}(+\mathrm{v} 29 \mathrm{~b}+\mathrm{v} 30 \mathrm{~b})$ & 5.87 & 6.57 & 6.61 & 7.38 & 6.46 \\
\hline AR (+v29b quantified) & 6.24 & 6.49 & 6.64 & 7.44 & 7.13 \\
\hline AR (+v30b quantified) & 5.87 & 6.57 & 6.59 & 7.34 & 6.40 \\
\hline Leading indicators model 1 & 6.46 & 6.19 & 6.38 & 6.37 & $5.85 *$ \\
\hline Leading indicators model 2 & 6.83 & 7.00 & 8.35 & $6.08 *$ & 7.65 \\
\hline
\end{tabular}

v29: Trend of activity compared with preceding months

v30: Assessment of order books

b: balance

Italics: best model without survey information

Bold: Better forecast performance than best model without survey information

* Best model 


\section{Table B.4}

qv4: Industry Production Index. Year-on-year growth rates of raw data

Average RMSE - Recursive forecasts from January 2002 to December 2005

\begin{tabular}{|c|c|c|c|c|c|}
\hline Models without survey information & 1 month & 2 months & 3 months & 6 months & 12 months \\
\hline $\mathrm{AR}$ & 1.47 & 1.57 & 1.69 & 2.35 & 3.06 \\
\hline ARIMA & 10.06 & 10.64 & 10.86 & 14.36 & 15.71 \\
\hline TAR & 14.86 & 16.29 & 22.51 & 33.58 & 52.52 \\
\hline VAR industry (a) & 1.53 & 1.53 & 1.40 & 1.64 & 1.57 \\
\hline Models with survey information & 1 month & 2 months & 3 months & 6 months & 12 months \\
\hline $\mathrm{AR}(+\mathrm{v} 7 \mathrm{~b})$ & $1.37 *$ & $1.39 *$ & $1.39 *$ & $1.55 *$ & 1.66 \\
\hline AR (+v7b quantified) & 1.48 & 1.49 & 1.46 & 1.59 & 1.60 \\
\hline Leading indicators model 1 & 1.45 & 1.53 & 1.44 & 1.96 & 1.38 \\
\hline Leading indicators model 2 & 1.49 & 1.33 & 1.73 & 1.95 & 2.80 \\
\hline VAR-industry (a) $(+v 7 b$ quantified $+v 8 b$ quantified $)$ & 1.48 & 1.58 & 1.54 & 1.61 & $1.56^{*}$ \\
\hline
\end{tabular}

v7: Production expectations for the months ahead

v8: Selling price expectations for the months ahead

b: balance

Italics: best model without survey information

Bold: Better forecast performance than best model without survey information

* Best model 


\section{Table B.5}

qv5: Industry Producer Price Index. Year-on-year growth rates of raw data

Average RMSE - Recursive forecasts from January 2002 to December 2005

\begin{tabular}{|c|c|c|c|c|c|}
\hline Models without survey information & 1 month & 2 months & 3 months & 6 months & 12 months \\
\hline $\mathrm{AR}$ & $0.42 *$ & $0.68 *$ & $0.88 *$ & 1.37 & 2.04 \\
\hline ARIMA & 2.93 & 4.94 & 6.48 & 10.04 & 15.08 \\
\hline TAR & 4.88 & 6.76 & 8.57 & 15.01 & 23.74 \\
\hline VAR industry (a) & 0.44 & 0.70 & 0.90 & 1.42 & 2.15 \\
\hline Models with survey information & 1 month & 2 months & 3 months & 6 months & 12 months \\
\hline $\mathrm{AR}(+\mathrm{v} 8 \mathrm{~b})$ & 0.44 & 0.70 & 0.91 & 1.42 & 2.15 \\
\hline AR (+v8b quantified) & 0.43 & 0.69 & 0.89 & 1.39 & 2.10 \\
\hline Leading indicators model 1 & 1.56 & 1.49 & 1.44 & $1.28 *$ & $1.84 \%$ \\
\hline Leading indicators model 2 & 1.95 & 1.55 & 1.66 & 3.13 & 4.63 \\
\hline VAR-industry (a) (+v7b quantified $+v 8 b$ quantified) & 0.44 & 0.71 & 0.92 & 1.41 & 2.12 \\
\hline
\end{tabular}

v7: Production expectations for the onths ahead

v8: Selling price expectations for the months ahead

b: balance

Italics: best model without survey information

Bold: Better forecast performance than best model without survey information

* Best model 


\section{Table B.6}

qv6: Number of new car registrations. Year-on-year growth rates of raw data

Average RMSE - Recursive forecasts from January 2002 to December 2005

\begin{tabular}{|c|c|c|c|c|c|}
\hline Models without survey information & 1 month & 2 months & 3 months & 6 months & 12 months \\
\hline AR & $4.95 *$ & 5.09 & $5.37 *$ & $5.33 *$ & 5.19 \\
\hline ARIMA & 40.81 & 42.26 & 43.82 & 38.38 & 40.65 \\
\hline TAR & 77.25 & 79.33 & 78.06 & 81.21 & 116.51 \\
\hline Models with survey information & 1 month & 2 months & 3 months & 6 months & 12 months \\
\hline Leading indicators model 1 & 5.46 & 4.61* & 5.85 & 6.31 & $5.14 *$ \\
\hline Leading indicators model 2 & 5.76 & 6.78 & 6.95 & 6.01 & 8.16 \\
\hline
\end{tabular}

Italics: best model without survey information

Bold: Better forecast performance than best model without survey information

* Best model 


\section{Table B.7}

qv7: Retail Deflated turnover index : Year-on-year growth rates of raw data Average RMSE - Recursive forecasts from January 2002 to December 2005

\begin{tabular}{|c|c|c|c|c|c|}
\hline Models without survey information & 1 month & 2 months & 3 months & 6 months & 12 months \\
\hline AR & $1.11^{*}$ & $1.12 *$ & $1.13^{*}$ & $1.26^{*}$ & 1.42 \\
\hline ARIMA & 8.79 & 8.48 & 7.92 & 8.62 & 9.13 \\
\hline TAR & 14.20 & 14.24 & 14.34 & 17.04 & 19.53 \\
\hline MK-TAR & 1.89 & 3.14 & 2.48 & 2.27 & 7.15 \\
\hline Models with survey information & 1 month & 2 months & 3 months & 6 months & 12 months \\
\hline $\mathrm{AR}(+\mathrm{v} 34 \mathrm{~b})$ & 1.25 & 1.24 & 1.22 & 1.31 & $1.39 *$ \\
\hline $\mathrm{AR}(+\mathrm{v} 35 \mathrm{~b})$ & 1.31 & 1.28 & 1.25 & 1.44 & 1.59 \\
\hline $\mathrm{AR}(+\mathrm{v} 36 \mathrm{~b})$ & 1.42 & 1.37 & 1.34 & 1.48 & 1.46 \\
\hline $\mathrm{AR}(+\mathrm{v} 37 \mathrm{~b})$ & 1.31 & 1.29 & 1.28 & 1.37 & 1.47 \\
\hline$A R(+v 34 b+v 35 b+v 36 b+v 37 b)$ & 2.27 & 2.58 & 2.64 & 2.68 & 2.64 \\
\hline AR ( $+v 34 b$ quantified) & 1.23 & 1.22 & 1.22 & 1.32 & 1.49 \\
\hline AR ( $+v 35 b$ quantified) & 1.33 & 1.29 & 1.25 & 1.38 & 1.47 \\
\hline AR ( $+v 36 b$ quantified $)$ & 1.40 & 1.36 & 1.33 & 1.52 & 1.62 \\
\hline AR (+v37b quantified) & 1.32 & 1.29 & 1.24 & 1.35 & 1.47 \\
\hline Leading indicators model 1 & 1.22 & 1.19 & 1.28 & 1.71 & 1.91 \\
\hline Leading indicators model 2 & 1.24 & 1.17 & 1.21 & 1.42 & 1.59 \\
\hline
\end{tabular}

$\begin{array}{ll}\text { v34: Present business situation } & \text { v36: Orders placed with suppliers } \\ \text { v35: Assessment of stocks } & \text { v37: Expected business situation } \\ \text { b: balance } & \end{array}$

b: balance

Italics: best model without survey information

Bold: Better forecast performance than best model without survey information

* Best model 


\section{Table B.8}

qv8: Unemployment rate. Year-on-year growth rates of raw data

Average RMSE - Recursive forecasts from January 2002 to December 2005

\begin{tabular}{|c|c|c|c|c|c|}
\hline Models without survey information & 1 month & 2 months & 3 months & 6 months & 12 months \\
\hline $\mathrm{AR}$ & $2.44^{*}$ & $2.73^{*}$ & $2.94 *$ & 3.83 & 4.63 \\
\hline ARIMA & 20.31 & 21.27 & 22.81 & 29.29 & 47.49 \\
\hline TAR & 21.54 & 26.82 & 32.74 & 58.39 & 135.12 \\
\hline Models with survey information & 1 month & 2 months & 3 months & 6 months & 12 months \\
\hline $\mathrm{AR}(+\mathrm{v} 19 \mathrm{~b})$ & 2.47 & 2.85 & 3.15 & 4.20 & $4.56 *$ \\
\hline AR (+v19b quantified) & 2.48 & 2.80 & 3.03 & 3.98 & 4.98 \\
\hline MK-TAR(+v19b) & 2.51 & 5.72 & 8.63 & 13.06 & 28.89 \\
\hline Leading indicators model 1 & 3.81 & 3.85 & 3.67 & 3.66 & 7.16 \\
\hline Leading indicators model 2 & 5.00 & 4.85 & 4.24 & $3.56 *$ & 8.95 \\
\hline
\end{tabular}

v19: Unemployment expectations over next 12 months

b: balance

Italics: best model without survey information

Bold: Better forecast performance than best model without survey information

* Best model 


\section{Table B.9}

qv9: Industry Gross value added. Year-on-year growth rates of raw data

Average RMSE - Recursive forecasts from 1st quarter 2002 to 4th quarter 2005

\begin{tabular}{|c|c|c|c|}
\hline Models without survey information & 1 quarter & 2 quarters & 4 quarters \\
\hline AR & 1.79 & 1.98 & 2.11 \\
\hline ARIMA & 8.00 & 9.95 & 10.34 \\
\hline TAR & 16.97 & 16.46 & 15.54 \\
\hline MK-TAR & 2.61 & 3.27 & $2.09 *$ \\
\hline VAR- supply & 2.27 & 2.96 & 2.94 \\
\hline Models with survey information & 1 quarter & 2 quarters & 4 quarters \\
\hline $\mathrm{AR}(+\mathrm{ICI})$ & 2.61 & 3.06 & 3.39 \\
\hline MK-TAR(+ICI) & 2.34 & 2.57 & 2.25 \\
\hline Leading indicators model 1 & $1.57 *$ & $1.95 *$ & 3.44 \\
\hline Leading indicators model 2 & 1.69 & 2.55 & 3.16 \\
\hline VAR- supply (+ESI) & 1.95 & 2.15 & 2.15 \\
\hline
\end{tabular}

VAR-supply: Industry Gross value added + Construction + Wholesale and retail trade + Financial intermediation

Italics: best model without survey information

Bold: Better forecast performance than best model without survey information

* Best model 


\section{Table B.10}

qv10: Construction Gross value added. Year-on-year growth rates of raw data

Average RMSE - Recursive forecasts from 1st quarter 2002 to 4th quarter 2005

\begin{tabular}{|c|c|c|c|}
\hline Models without survey information & 1 quarter & 2 quarters & 4 quarters \\
\hline AR & $1.58 *$ & $1.74 *$ & 1.99 \\
\hline ARIMA & 8.03 & 9.08 & 11.12 \\
\hline TAR & 12.14 & 15.24 & 19.55 \\
\hline MK-TAR & 1.81 & 3.11 & 4.13 \\
\hline VAR- supply & 2.28 & 2.96 & 2.94 \\
\hline Models with survey information & 1 quarter & 2 quarters & 4 quarters \\
\hline $\mathrm{AR}(+\mathrm{CCI})$ & 2.24 & 2.29 & $1.55^{*}$ \\
\hline Leading indicators model 1 & 1.72 & 1.79 & 3.29 \\
\hline Leading indicators model 2 & 2.48 & 2.67 & 3.65 \\
\hline VAR- supply (+ESI) & 1.99 & 1.96 & 1.73 \\
\hline
\end{tabular}

VAR-supply: Industry Gross value added + Construction + Wholesale and retail trade + Financial intermediation

Italics: best model without survey information

Bold: Better forecast performance than best model without survey information

* Best model 


\section{Table B.11}

qv11: Wholesale and retail trade \& other Gross value added. Year-on-year growth rates of raw data

Average RMSE - Recursive forecasts from 1st quarter 2002 to 4th quarter 2005

\begin{tabular}{|c|c|c|c|}
\hline Models without survey information & 1 quarter & 2 quarters & 4 quarters \\
\hline AR & 1.20 & 1.22 & 1.19 \\
\hline ARIMA & 5.41 & 5.57 & 5.22 \\
\hline TAR & 8.37 & 7.93 & 9.70 \\
\hline VAR-supply & 1.24 & 1.16 & 1.42 \\
\hline Models with survey information & 1 quarter & 2 quarters & 4 quarters \\
\hline $\mathrm{AR}(+\mathrm{v} 34 \mathrm{~b})$ & 1.17 & 0.99 & 1.08 \\
\hline AR (+v34b quantified) & 1.16 & 1.00 & 0.99 \\
\hline Leading indicators model 1 & $0.91 *$ & 1.08 & 1.64 \\
\hline Leading indicators model 2 & 1.04 & 1.03 & 1.51 \\
\hline VAR- supply (+ESI) & 1.14 & $0.94 *$ & $0.82 *$ \\
\hline
\end{tabular}

VAR-supply: Industry Gross value added + Construction + Wholesale and retail trade + Financial intermediation

v34: Present business situation

b: balance

Italics: best model without survey information

Bold: Better forecast performance than best model without survey information

* Best model 


\section{Table B.12}

qv12: Financial intermediation Gross value added. Year-on-year growth rates of raw data

Average RMSE - Recursive forecasts from 1st quarter 2002 to 4th quarter 2005

\begin{tabular}{|c|c|c|c|}
\hline Models without survey information & 1 quarter & 2 quarters & 4 quarters \\
\hline $\mathrm{AR}$ & 1.05 & 1.49 & 1.87 \\
\hline ARIMA & 4.28 & 5.99 & 7.73 \\
\hline TAR & 8.25 & 9.69 & 13.36 \\
\hline VAR-supply & 1.07 & 1.57 & 2.04 \\
\hline Models with survey information & 1 quarter & 2 quarters & 4 quarters \\
\hline $\mathrm{AR}(+\mathrm{v} 13 \mathrm{~b})$ & 11.64 & 13.76 & 22.66 \\
\hline $\mathrm{AR}(+\mathrm{v} 14 \mathrm{~b})$ & 13.62 & 15.47 & 19.29 \\
\hline $\mathrm{AR}(+\mathrm{v} 13 \mathrm{~b}+\mathrm{v} 14 \mathrm{~b})$ & 1.05 & 1.58 & 2.23 \\
\hline $\mathrm{AR}(+\mathrm{v} 13 \mathrm{~b}$ quantified $)$ & 11.65 & 13.77 & 22.67 \\
\hline AR $(+v 14 b$ quantified $)$ & 13.62 & 15.47 & 19.29 \\
\hline Leading indicators model 1 & 1.45 & 1.69 & $1.71 *$ \\
\hline Leading indicators model 2 & 1.10 & 1.64 & 1.78 \\
\hline VAR- supply (+ESI) & $1.00 *$ & $1.42 *$ & 1.86 \\
\hline
\end{tabular}

VAR-supply: Industry Gross value added + Construction + Wholesale and retail trade + Financial intermediation

v13: Financial situation over last 12 months

v14: Financial situation over next 12 months

b: balance

Italics: best model without survey information

Bold: Better forecast performance than best model without survey information

* Best model 


\section{Table B.13}

qv13: Savings rate. Year-on-year growth rates of raw data

Average RMSE - Recursive forecasts from 4th quarter 2001 to 3rd quarter 2005

\begin{tabular}{|c|c|c|c|}
\hline Models without survey information & 1 quarter & 2 quarters & 4 quarters \\
\hline $\mathrm{AR}$ & 7.94 & 9.70 & 8.27 \\
\hline ARIMA & 32.27 & 42.92 & 50.93 \\
\hline TAR & 53.88 & 58.98 & 62.78 \\
\hline VAR- savings & 9.27 & 9.14 & 12.45 \\
\hline Models with survey information & 1 quarter & 2 quarters & 4 quarters \\
\hline $\mathrm{AR}(+\mathrm{v} 22 \mathrm{~b})$ & 11.65 & 13.77 & 22.67 \\
\hline $\mathrm{AR}(+\mathrm{v} 23 \mathrm{~b})$ & 13.62 & 15.47 & 19.29 \\
\hline $\mathrm{AR}(+\mathrm{v} 22+\mathrm{v} 23 \mathrm{~b})$ & 17.45 & 17.99 & 22.62 \\
\hline $\mathrm{AR}(+\mathrm{v} 22 \mathrm{~b}$ quantified $)$ & 11.64 & 13.76 & 22.66 \\
\hline AR $(+v 23 b$ quantified $)$ & 13.62 & 14.47 & 19.30 \\
\hline Leading indicators model 1 & $6.73 *$ & $7.24 *$ & $7.72 *$ \\
\hline Leading indicators model 2 & 8.86 & 8.55 & 9.55 \\
\hline VAR- savings $(+v 23 b+v 24 b)$ & 8.72 & 9.24 & 10.14 \\
\hline
\end{tabular}

VAR-savings: HCPI + Savings rate + GDP + Interests rates

v22: Savings at present

v24: Statement on financial situation of household

v23: Savings over next 12 months

b: balance

Italics: best model without survey information

Bold: Better forecast performance than best model without survey information

* Best model 


\section{Table B.14}

qv14: Gross Domestic Product. Year-on-year growth rates of raw data

Average RMSE - Recursive forecasts from 1st quarter 2002 to 4th quarter 2005

\begin{tabular}{lccc}
\hline Models without survey information & 1 quarter & 2 quarters & 4 quarters \\
\hline AR & 0.94 & 1.02 & 1.11 \\
ARIMA & 4.15 & 4.80 & 4.69 \\
TAR & 7.93 & 10.49 & 14.16 \\
MK-TAR & 1.10 & 1.86 & 2.29 \\
VAR-total & $0.70^{*}$ & 0.67 & $0.76^{*}$ \\
VAR-consumption & 0.89 & 1.10 & 1.57 \\
VAR-savings & 1.28 & 1.67 & 1.88 \\
VAR-exports & 0.94 & 1.24 & 2.53 \\
\hline
\end{tabular}

\begin{tabular}{lccc}
\hline Models with survey information & 1 quarter & 2 quarters & 4 quarters \\
\hline $\mathrm{AR}(+\mathrm{ESI})$ & 0.87 & 0.89 & 0.91 \\
$\mathrm{AR}(+\mathrm{v} 15 \mathrm{~b})$ & 0.90 & 0.90 & 0.94 \\
$\mathrm{AR}(+\mathrm{v} 16 \mathrm{~b})$ & 0.80 & 0.85 & 0.86 \\
$\mathrm{AR}(+\mathrm{ESI}+\mathrm{v} 15 \mathrm{~b}+\mathrm{v} 16 \mathrm{~b})$ & 1.11 & 1.41 & 1.39 \\
$\mathrm{AR}(+\mathrm{v} 15$ quantified) & 0.94 & 1.00 & 1.09 \\
$\mathrm{AR}(+\mathrm{v} 16$ quantified) & 0.94 & 1.00 & 1.11 \\
MK-TAR (+v1) & 1.19 & 1.17 & 1.59 \\
Leading indicators model 1 & 0.96 & $\mathbf{0 . 6 4}$ & 2.14 \\
Leading indicators model 2 & 1.04 & 1.66 & 1.89 \\
VAR-total (+ ESI) & 0.99 & 0.93 & 0.88 \\
VAR-exports (+v5b) & 1.01 & 1.13 & 1.82 \\
VAR-consumption $(+\mathrm{CCI})$ & 0.98 & 1.07 & 0.97 \\
VAR-consumption (+v14b+v16b+v18b+v19b) & 1.18 & 1.09 & 0.85 \\
VAR-savings (+v23b+v24b) & 1.68 & 1.66 & 1.44 \\
\hline
\end{tabular}

v14: Financial situation over next 12 months

v15: General economic situation over last 12 months v16: General economic situation over next 12 months

v18: Price trends over next 12 months

v19: Unemployment expectations over next 12 months

v23: Savings over next 12 months

v24: Statement on financial situation of household

b: balance

VAR-total: HCPI+ GDP + Unemployment

VAR-consumption: Consumption + HCPI + GDP + Unemployment + Interest rates

VAR-savings: Savings rate + GDP + HCPI + Interest rates

VAR-exports: GDP + Exports of goods + Exchange rate

Italics: best model without survey information

Bold: Better forecast performance than best model without survey information

* Best model 


\section{Table B.15}

qv15: Gross fixed capital formation: construction work - other constructions. Year-on-year growth rates of raw data Average RMSE - Recursive forecasts from 4th quarter 2001 to 3rd quarter 2005

\begin{tabular}{|c|c|c|c|}
\hline Models without survey information & 1 quarter & 2 quarters & 4 quarters \\
\hline AR & 2.55 & 2.93 & 2.69 \\
\hline ARIMA & 11.96 & 12.82 & 13.49 \\
\hline TAR & 21.37 & 21.41 & 21.61 \\
\hline MK-TAR & 2.75 & 3.55 & 3.73 \\
\hline VAR- building & $2.06^{*}$ & $1.43 *$ & 3.22 \\
\hline Models with survey information & 1 quarter & 2 quarters & 4 quarters \\
\hline AR $(+v 29 b)$ & 2.81 & 2.82 & 3.32 \\
\hline $\mathrm{AR}(+\mathrm{v} 30 \mathrm{~b})$ & 2.56 & 2.44 & 2.55 \\
\hline $\mathrm{AR}(+\mathrm{v} 29 \mathrm{~b}+\mathrm{v} 30 \mathrm{~b})$ & 4.80 & 4.93 & 7.00 \\
\hline AR (+v29b quantified) & 2.76 & 3.33 & 3.29 \\
\hline $\mathrm{AR}(+\mathrm{v} 30 \mathrm{~b}$ quantified $)$ & 2.57 & 2.66 & 2.74 \\
\hline Leading indicators model 1 & 2.74 & 2.71 & 2.90 \\
\hline Leading indicators model 2 & 2.88 & 2.88 & 3.84 \\
\hline VAR-building (a) (+CCI) & 5.17 & 3.74 & $2.45 *$ \\
\hline VAR-building (b) $(+v 31 b+v 32 b)$ & 4.76 & 3.05 & 3.85 \\
\hline
\end{tabular}

VAR-building: construction + Building permits index + construction work (other constructions) + construction work (housing)

\footnotetext{
v29: Trend of activity compared with preceding months

v30: Assessment of order books

v31: Employment expectations for the months ahead

v32: Price expectations for the months ahead

b: balance
}

Italics: best model without survey information

Bold: Better forecast performance than best model without survey information

* Best model 


\section{Table B.16}

qv16: Gross fixed capital formation: metal products and machinery. Year-on-year growth rates of raw data Average RMSE - Recursive forecasts from 4th quarter 2001 to 3rd quarter 2005

\begin{tabular}{|c|c|c|c|}
\hline Models without survey information & 1 quarter & 2 quarters & 4 quarters \\
\hline AR & 2.15 & 3.44 & 4.81 \\
\hline ARIMA & 8.41 & 14.31 & 17.32 \\
\hline TAR & 21.73 & 34.09 & 57.61 \\
\hline VAR- industry (b) & $1.67 *$ & 2.91 & 3.94 \\
\hline Models with survey information & 1 quarter & 2 quarters & 4 quarters \\
\hline $\mathrm{AR}(+\mathrm{v} 3 \mathrm{~b})$ & 1.90 & $2.76 *$ & 4.21 \\
\hline $\operatorname{AR}(+v 7 b)$ & 2.89 & 3.77 & 6.63 \\
\hline $\mathrm{AR}(+\mathrm{v} 3 \mathrm{~b}+\mathrm{v} 7 \mathrm{~b})$ & 5.59 & 9.03 & 37.16 \\
\hline AR (+v3b quantified) & 1.94 & 2.78 & 4.18 \\
\hline AR (+v7b quantified) & 3.23 & 3.98 & 5.04 \\
\hline MK-TAR(+v7b) & 2.89 & 5.37 & 6.75 \\
\hline Leading indicators model 1 & 1.72 & 3.23 & 4.01 \\
\hline Leading indicators model 2 & 2.44 & 4.56 & 7.95 \\
\hline VAR-industry (b) $(+\mathrm{ICI})$ & 2.26 & 3.15 & $2.34 *$ \\
\hline
\end{tabular}

VAR-industry (b): Industry production index + Industry producer price index + metal products and machinery
v3: Production trend observed in recent months
v7: Production expectations for the months ahead
b: balance

Italics: best model without survey information

Bold: Better forecast performance than best model without survey information

* Best model 


\section{Table B.17}

qv17: Exports of goods. Year-on-year growth rates of raw data

Average RMSE - Recursive forecasts from 1st quarter 2002 to 4th quarter 2005

\begin{tabular}{|c|c|c|c|}
\hline Models without survey information & 1 quarter & 2 quarters & 4 quarters \\
\hline $\mathrm{AR}$ & 3.38 & 5.22 & 6.12 \\
\hline ARIMA & 5.62 & 5.68 & 6.61 \\
\hline TAR & 22.23 & 30.80 & 44.41 \\
\hline VAR- exports & 3.39 & 5.76 & 9.80 \\
\hline Models with survey information & 1 quarter & 2 quarters & 4 quarters \\
\hline $\operatorname{AR}(+11 b)$ & 4.63 & 6.02 & 5.13 \\
\hline $\mathrm{AR}(+\mathrm{v} 5 \mathrm{~b})$ & 4.15 & 5.75 & $4.39 *$ \\
\hline $\operatorname{AR}(+v 11 b+v 5 b)$ & 4.62 & 6.73 & 7.77 \\
\hline $\mathrm{AR}(+\mathrm{v} 11 \mathrm{~b}$ quantified $)$ & 4.39 & 7.25 & 8.74 \\
\hline $\mathrm{AR}(+\mathrm{v} 5 \mathrm{~b}$ quantified $)$ & 3.86 & 6.71 & 8.83 \\
\hline MK-TAR(+v11b) & 3.01 & 5.65 & 6.92 \\
\hline Leading indicators model 1 & 2.98 & $1.90 *$ & 6.42 \\
\hline Leading indicators model 2 & $2.39 *$ & 2.68 & 6.58 \\
\hline VAR-exports $(+\mathrm{v} 5 \mathrm{~b})$ & 3.54 & 4.47 & 4.41 \\
\hline
\end{tabular}

VAR-exports: GDP + Exports of goods + Exchange rate

v5: Assessment of export order-book levels

v11: Export expectations for the months ahead

b: balance

Italics: best model without survey information

Bold: Better forecast performance than best model without survey information

* Best model 


\section{Table B.18}

qv18: Consumption. Year-on-year growth rates of raw data

Average RMSE - Recursive forecasts from 1st quarter 2002 to 4th quarter 2005

\begin{tabular}{|c|c|c|c|}
\hline Models without survey information & 1 quarter & 2 quarters & 4 quarters \\
\hline $\mathrm{AR}$ & 1.16 & 1.03 & 0.87 \\
\hline ARIMA & 5.62 & 5.67 & 6.60 \\
\hline TAR & 7.65 & 7.15 & 6.42 \\
\hline MK-TAR & 1.31 & 1.41 & 7.52 \\
\hline VAR- consumption & 1.27 & 1.19 & $0.80 *$ \\
\hline Models with survey information & 1 quarter & 2 quarters & 4 quarters \\
\hline $\mathrm{AR}(+\mathrm{v} 20 \mathrm{~b})$ & 1.14 & 1.01 & 0.92 \\
\hline $\mathrm{AR}(+\mathrm{v} 20 \mathrm{~b}$ quantified $)$ & 1.19 & 1.06 & 0.86 \\
\hline Leading indicators model 1 & $1.04 \%$ & $0.95 *$ & 0.84 \\
\hline Leading indicators model 2 & 1.11 & 1.38 & 1.89 \\
\hline VAR-consumption (a) (+ CCI) & 1.33 & 1.29 & 0.83 \\
\hline VAR-consumption (b) $(+v 14 b+v 16 b+v 18 b+v 19 b)$ & 1.43 & 1.18 & 0.99 \\
\hline
\end{tabular}

VAR-consumption: Consumption + HCPI + GDP + Unemployment + Interest rates

v14: Financial situation over next 12 months

v16: General economic situation over next 12 months

v18: Price trends over next 12 months

v19: Unemployment expectations over next 12 months

v20: Major purchases at present

b: balance

Italics: best model without survey information

Bold: Better forecast performance than best model without survey information

* Best model 


\section{Table B.19}

qv19: Gross fixed capital formation: construction work - housing. Year-on-year growth rates of raw data Average RMSE - Recursive forecasts from 4th quarter 2001 to 3rd quarter 2005

\begin{tabular}{|c|c|c|c|}
\hline Models without survey information & 1 quarter & 2 quarters & 4 quarters \\
\hline $\mathrm{AR}$ & 2.86 & 3.31 & 3.14 \\
\hline ARIMA & 13.31 & 14.72 & 19.81 \\
\hline TAR & 16.98 & 18.92 & 21.21 \\
\hline VAR- building & $2.78^{*}$ & 3.27 & 2.51 \\
\hline Models with survey information & 1 quarter & 2 quarters & 4 quarters \\
\hline $\mathrm{AR}(+\mathrm{v} 26 \mathrm{~b})$ & 4.85 & 5.29 & 5.70 \\
\hline AR (+v26b quantified) & 4.61 & 4.42 & 4.92 \\
\hline Leading indicators model 1 & 2.85 & $2.69 *$ & $2.45 *$ \\
\hline Leading indicators model 2 & 3.64 & 4.86 & 5.78 \\
\hline VAR-building (a) (+CCI) & 5.09 & 3.91 & 3.57 \\
\hline VAR-building (b) $(+v 31 b+v 32 b)$ & 4.71 & 4.07 & 5.22 \\
\hline
\end{tabular}

VAR-building: construction + Building permits index + construction work (other constructions) + construction work (housing)

v26: Purchase or build a home within the next 2 years

v31: Employment expectations for the months ahead

v32: Price expectations for the months ahead

b: balance

Italics: best model without survey information

Bold: Better forecast performance than best model without survey information

* Best model 